\title{
Aberrant accumulation of PTTG1 induced by a mutated thyroid hormone $\beta$ receptor inhibits mitotic progression
}

\author{
Hao Ying, ${ }^{1}$ Fumihiko Furuya, ${ }^{1}$ Li Zhao, ${ }^{1}$ Osamu Araki,, ${ }^{1}$ Brian L. West, ${ }^{2}$ John A. Hanover, ${ }^{3}$ \\ Mark C. Willingham, ${ }^{4}$ and Sheue-yann Cheng ${ }^{1}$ \\ ${ }^{1}$ Laboratory of Molecular Biology, Center for Cancer Research, National Cancer Institute, NIH, Bethesda, Maryland, USA. \\ 2Plexxikon, Inc., Berkeley, California, USA. ${ }^{2}$ Laboratory of Cellular Biochemistry and Biology, NIDDK, NIHealth, Bethesda, Maryland, USA. \\ ${ }^{4}$ Wake Forest University, Winston-Salem, North Carolina, USA.
}

\begin{abstract}
Overexpression of pituitary tumor-transforming 1 (PTTG1) is associated with thyroid cancer. We found elevated PTTG1 levels in the thyroid tumors of a mouse model of follicular thyroid carcinoma (TR $\beta^{P V / P V}$ mice). Here we examined the molecular mechanisms underlying elevated PTTG1 levels and the contribution of increased PTTG1 to thyroid carcinogenesis. We showed that PTTG1 was physically associated with thyroid hormone $\beta$ receptor $(\operatorname{TR} \beta)$ as well as its mutant, designated PV. Concomitant with thyroid hormone-induced (T3-induced) degradation of TR $\beta$, PTTG1 proteins were degraded by the proteasomal machinery, but no such degradation occurred when PTTG1 was associated with PV. The degradation of PTTG1/TR $\beta$ was activated by the direct interaction of the liganded TR $\beta$ with steroid receptor coactivator 3 (SRC-3), which recruits proteasome activator PA28 $\gamma$. PV, which does not bind T3, could not interact directly with SRC-3/PA28 $\gamma$ to activate proteasome degradation, resulting in elevated PTTG1 levels. The accumulated PTTG1 impeded mitotic progression in cells expressing PV. Our results unveil what we believe to be a novel mechanism by which PTTG1, an oncogene, is regulated by the liganded TR $\beta$. The loss of this regulatory function in PV led to an aberrant accumulation of PTTG1 disrupting mitotic progression that could contribute to thyroid carcinogenesis.
\end{abstract}

\section{Introduction}

Follicular and papillary thyroid carcinomas are the most common thyroid malignancies. Although both are well-differentiated cancers, each has distinguishable morphological and pathological characteristics (1). Follicular thyroid carcinoma has a greater tendency than does papillary cancer to metastasize to distant sites. Such distant metastasis predicts a poor response to treatment and subsequent progression and mortality from thyroid cancer. Despite recent progress in the identification of key genetic alterations and aberrant molecular pathways, the precise mechanisms underlying the initiation and progression of follicular thyroid cancer are not fully understood.

The development of a mouse model of follicular thyroid cancer $\left(T R \beta^{P V / P V}\right.$ mice) has provided a valuable tool to elucidate the molecular basis underlying thyroid carcinogenesis (2). The $T R \beta^{P V / P V}$ mouse was created by a targeted mutation of thyroid hormone $\beta$ receptor $(\mathrm{TR} \beta)$ via homologous recombination and the Cre-LoxP system (3). The TR $\beta$ mutant (referred to here as $\mathrm{PV})$ was identified in a patient with resistance to thyroid hormone (RTH) (4). RTH is caused by mutations of the TR $\beta$ gene and manifests symptoms as a result of decreased sensitivity to

Nonstandard abbreviations used: F-, Flag-tagged; FH-PV cells, HeLa cells stably expressing Flag-tagged PV; FH-TR $\beta 1$ cells, HeLa cells stably expressing Flag-tagged TR $\beta 1$; GST, glutathione-S-transferase; GST-PTTG $\Delta \mathrm{C}$, GST conjugated to aminoterminal PTTG1; GST-PTTG $\Delta \mathrm{N}$, GST conjugated to carboxyterminal PTTG1; p-, phosphorylated; PA28 $\gamma$, proteasome activator $28 \gamma$; PTTG1, pituitary tumor-transforming 1 ; PV, TR $\beta$ mutant; RTH, resistance to thyroid hormone; SRC-3, steroid hormone receptor coactivator 3; T3, thyroid hormone; TR, thyroid hormone receptor; TR $\beta$, thyroid hormone $\beta$ receptor; TR $\beta 1(170-461)$, truncated TR $\beta 1$ lacking the DNA-binding domain but retaining the ligand-binding domain; UAS, upstream activating sequence.

Conflict of interest: The authors have declared that no conflict of interest exists. Citation for this article: J. Clin. Invest. 116:2972-2984 (2006). doi:10.1172/JCI28598. the thyroid hormone (T3) in target tissues (5). PV has a $\mathrm{C}$ insertion at codon 448 that produces a frame shift in the carboxyterminal 16 amino acids of TR $\beta 1$ (4). PV has completely lost T3 binding and exhibits potent dominant-negative activity (6). As $T R \beta^{P V / P V}$ mice age, they spontaneously develop follicular thyroid carcinoma similar to human thyroid cancer, with pathological progression from hyperplasia to vascular invasion, capsular invasion, anaplasia, and eventually metastasis $(2,7,8)$.

One important, but not well-understood, genetic alteration is that of chromosomal aberrations in thyroid carcinomas. Chromosomal instability has been observed in follicular thyroid tumors, including the genetic losses in such regions as $2 \mathrm{p}, 2 \mathrm{q}, 3 \mathrm{p}, 7 \mathrm{q}, 9$, $13 q$, and $22 q(9-11)$. Recently, using spectral karyotyping analysis, we discovered chromosomal aberrations in 7 cell lines derived from thyroid tumors of $T R \beta^{P V / P V}$ mice (12). These cell lines exhibit abnormal karyotypes and a variety of structural chromosomal aberrations, including common recurrent translocations and deletions, raising the possibility that induction of chromosomal instability may be one of the key genetic events contributing to the thyroid carcinogenesis in $T R \beta^{P V / P V}$ mice (12).

To search for genes underlying the chromosomal aberrations in $T R \beta^{P V / P V}$ mice, we turned our attention to the genes that are altered during thyroid carcinogenesis as detected by cDNA microarray analyses (7). One significantly activated gene that caught our attention was pituitary tumor-transforming 1 (PTTG1). PTTG1, also known as securin, is a critical mitotic checkpoint protein that helps hold sister chromatids together before entering anaphase (13). It was originally isolated from GH4 pituitary cells and shown to cause cell transformation in vitro and to induce tumor formation in vivo (14). Overexpression of PTTG1 has been detected in human thyroid carcinomas $(15,16)$, colorectal carcinoma (17), pituitary 


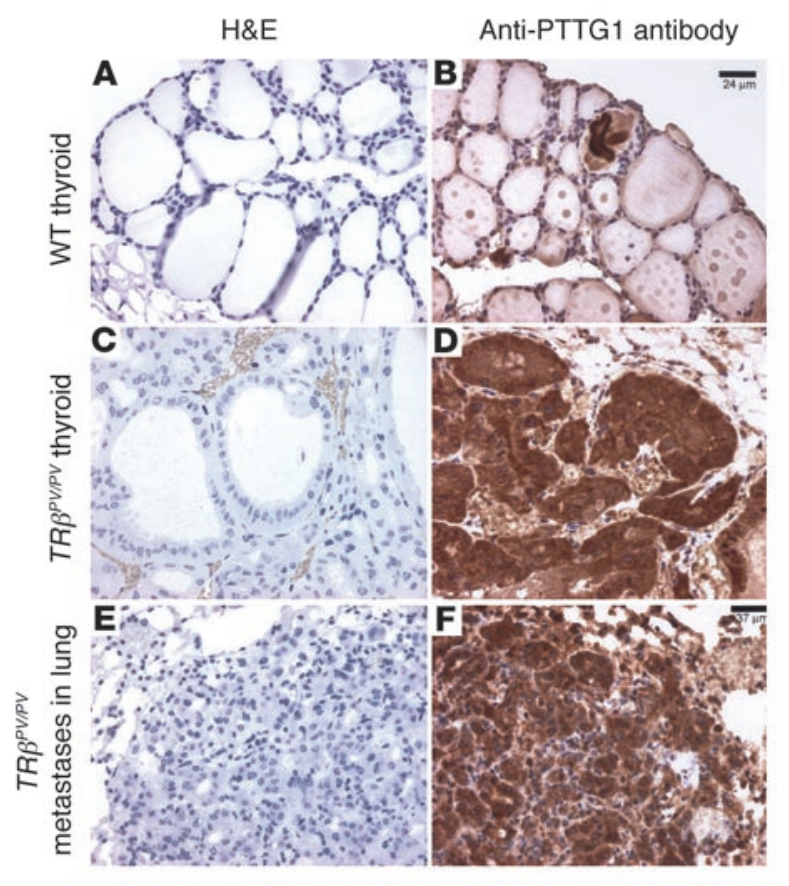

adenomas (18), and hematopoietic neoplasms (19). Importantly, PTTG1 was found to induce genetic instability in a variety of cells, including thyroid cells (20-22).

In the present study, we sought to understand the molecular basis by which PV increased the accumulation of cellular PTTG1 levels. We discovered that PTTG1 physically interacted with TR $\beta$ as well as PV and that the association of PTTG1 with the T3-bound TR $\beta$ resulted in the degradation of PTTG1 via the proteasomal degradation machinery. A recent study has demonstrated the interaction of steroid hormone receptor coactivator 3 (SRC-3) with proteasome activator 28 $\gamma$ (PA28 $\gamma$ ) and that the degradation of SRC-3 is mediated by the PA28 $\gamma$ proteasome (23). We found that the direct interaction of TR $\beta$ with SRC-3 upon T3 binding activated the PA28 $\gamma$ proteasome-mediated degradation of PTTG1. In contrast, PV, which does not bind T3, could not form active complexes via direct interaction with SRC-3/PA28 $\gamma$. The resistance to degradation resulted in the aberrant accumulation of the cellular PTTG1 protein that inhibited mitotic progression. Thus, the present study reveals a novel function of a TR $\beta$ mutant that caused mitotic abnormalities via stabilization of cellular PTTG1 levels.

\section{Results}

Increased PTTG1 abundance in the metastatic thyroid carcinoma of $T R \beta^{P V / P V}$ mice. Histological immunostaining of tissues from $T R \beta^{P V / P V}$ mice revealed a marked increase in the abundance of PTTG1 visible in both nuclei and cytoplasm of these cells (Figure 1, D and F). The increase in PTTG1 occurred not only in the primary lesions of thyroid (Figure 1, compare B and D), but also in the lung metastases (Figure 1F). Quantitative analysis of the stain intensity showed 5.4- and 3.1-fold increases in the immunoreactivity of PTTG1 in the thyroid primary lesions and lung metastases, respectively, compared with thyroid in wild-type mice. These results are consistent with previous CDNA microarray analyses during thyroid carcinogenesis of $T R \beta^{P V / P V}$ mice showing the expression of PTTG1 mRNA in the primary lesions was increased

\section{Figure 1}

Increased abundance of PTTG1 in metastatic thyroid carcinomas of $T R \beta^{P V / P V}$ mice. Shown are thyroids from wild-type mice (A and $\mathbf{B}$ ), thyroids from $T R \beta^{P V / P V}$ mice (C and $\mathbf{D}$ ), and lung metastasis from $T R \beta^{P V I P V}$ mice ( $\mathbf{E}$ and $\mathbf{F})$ stained by $\mathrm{H} \& \mathrm{E}(\mathbf{A}, \mathbf{C}$, and $\mathbf{E})$ and immunostained by anti-PTTG1 antibody (B, D, and F) as described in Methods.

5.4-fold compared with the thyroids of wild-type mice. An increase in PTTG1 mRNA in TR $\beta^{P V / P V}$ mice has also been shown previously by quantitative RT-PCR (7). The observed increases in PTTG1 shown in Figure 1 could play an important role in thyroid carcinogenesis and thus stimulated investigations into its biochemical mechanisms and cellular consequences. The increase in PTTG1 mRNA in $T R \beta^{P V / P V}$ mice likely explains, at least in part, the increase in PTTG1 and further suggests some effect of PV on PTTG1 gene expression or mRNA stabilization. Since thyroid hormone receptors (TRs) and other nuclear receptors are known to participate in proteasome-mediated degradation pathways, in this study we investigated whether TR $\beta 1$ or PV operate through such mechanisms to directly modulate the cellular abundance of PTTG1.

PTTG1 interacts with TR $\beta 1$ and PV in vitro and in cells. We first tested the hypothesis that TR $\beta 1$ and PV could affect the stability of cellular PTTG1 via their interaction with PTTG1. Indeed, using glutathione-S-transferase (GST) pull-down assays, we found that PTTG1 was specifically associated with TR $\beta 1$ in vitro (Figure 2A, lane 4), because no signals in controls were detected when only agarose beads (lane 2) or agarose-GST (lane 3) was used. Analysis of the band intensities in Figure 2A, lanes 1 (input) and 4, showed that about $2 \%-4 \%$ of the total $\left[{ }^{35}\right.$ S]PTTG1 was bound to GST-TR $\beta 1$ under the experimental conditions. To localize the regions of TR $\beta 1$ with which PTTG1 interacted, a series of truncated $\left[{ }^{35} \mathrm{~S}\right]$-labeled TR $\beta 1$ proteins (Figure $2 \mathrm{C}$ ) were tested for their association with GST-PTTG1. Figure 2B shows that ED41 (domains $\mathrm{C}+\mathrm{D}+\mathrm{E}$ of TR $\beta 1$; lane 7) bound to GST-PTTG1 in a manner similar to intact TR $\beta 1$ (lane 6). However, when the DNA-binding domain was deleted in MD32, KD25, and KP24 (Figure 2B, lanes 8, 9, and 10, respectively), no binding to PTTG1 was detected, indicating that the interaction site of TR $\beta 1$ with PTTG1 requires the DNA-binding domain. To map the region of PTTG1 with which TR $\beta 1$ or PV interacts, GST was conjugated to aminoterminal PTTG1 (GSTPTTG1 $\Delta \mathrm{C}$ ) or carboxyterminal PTTG1 (GST-PTTG1 $\Delta$ N; Figure 2E). Figure 2D, lanes 5 and 6 , show that the full-length PTTG1 bound to TR $\beta 1$ with or without T3. A similar association of the full-length PTTG1 with PV was also detected (Figure 2D, lanes 7 and 8). The aminoterminal part of PTTG1 (Figure 2D, lanes 9-12) was sufficient for binding to TR $\beta 1$ (lanes 9 and 10) and PV (lanes 11 and 12). However, when the aminoterminal part was deleted, no binding was detected with either TR $\beta 1$ or PV (data not shown). Comparison of the intensity of the bands shown in the input lanes showed that about $3 \%-5 \%$ of total applied $\left[{ }^{35} \mathrm{~S}\right] \mathrm{TR} \beta 1$ (or truncated $\left[{ }^{35} \mathrm{~S}\right] \mathrm{TR} \beta 1$ ) or $\left[{ }^{35} \mathrm{~S}\right] \mathrm{PV}$ was bound to GST-PTTG1. These data indicate that the binding site of PTTG1 with TR $\beta 1$ or PV is located in the aminoterminal region of PTTG1 and the interaction of PTTG1 with TR $\beta 1$ or PV is T3 independent.

An interaction between endogenous PTTG 1 and TR $\beta 1$ or $\mathrm{PV}$ was also demonstrated in the thyroids of wild-type and $T R \beta^{P V / P V}$ mice by coimmunoprecipitation assays (Figure $3 \mathrm{~A}$ ). Western blot analysis (Figure $3 \mathrm{~A}$, compare lanes 1 and 2) confirmed the elevated PTTG1 levels in the thyroids of $T R \beta^{P V / P V}$ 


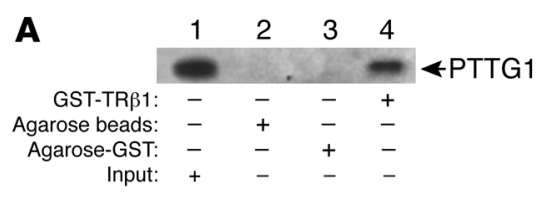

C

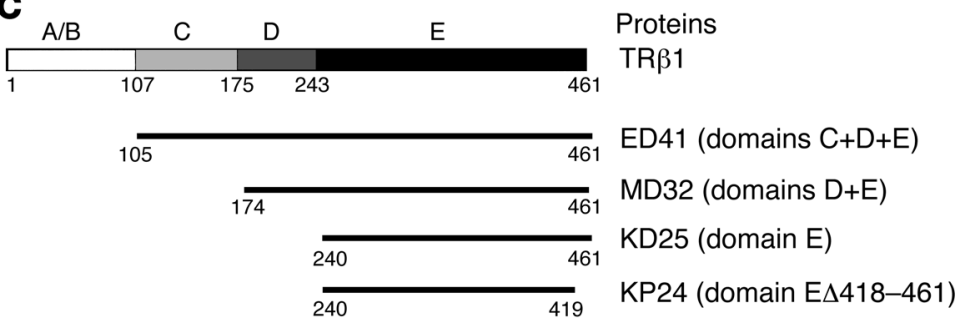

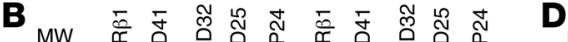

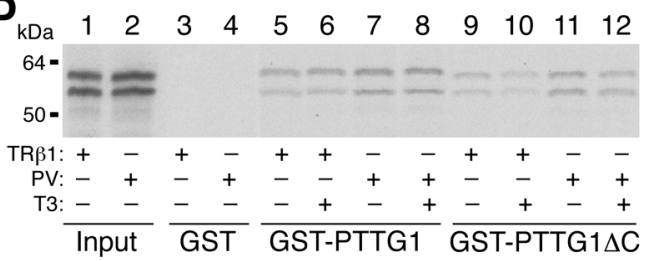

$\mathbf{E}$

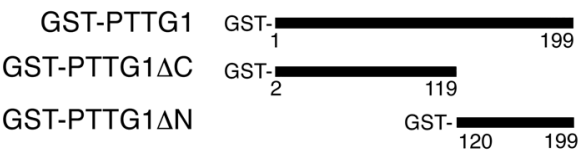

Figure 2

Analysis of the interaction of PTTG1 with TR $\beta 1$ or PV by GST pull-down assays. (A) [ ${ }^{35}$ S]-labeled PTTG1 (20 $\mu$ l) prepared by in vitro transcription/translation was incubated with agarose beads (lane 2), agarose-GST (lane 3), or GST-TR $\beta 1$ (lane 4) as described in Methods. Lane 1 shows the input $(1 \mu \mathrm{l})$ of [ ${ }^{35} \mathrm{~S}$ ]-labeled PTTG1. (B). Binding of truncated [35S]-labeled TR 31 to GST-PTTG1. Lanes $1-5$ show the input of [35S]-labeled TR $\beta 1$ and truncated TR $\beta 1$ proteins as marked (10\% of that in lanes $6-10)$. Lanes 6 and 7 show the binding of the full-length and truncated (domains $\mathrm{C}+\mathrm{D}+\mathrm{E}) \mathrm{TR} \beta 1$, respectively. The volumes of programmed lysates were adjusted such that equal amounts of full-length TR $\beta 1$, ED41, MD32, KD25, and KP24 protein were used in the binding assay. (C) Schematic representation of full-length and truncated TR $\beta 1$ proteins, with domains and boundaries indicated. (D) Binding of [35S]-labeled TR $\beta 1(10 \mu \mathrm{l})$ or [ $\left.{ }^{35} \mathrm{~S}\right]$-labeled PV (10 $\left.\mu \mathrm{l}\right)$ to GST-PTTG1 and GST-PTTG1 $\Delta \mathrm{C}$ in the presence (lanes 6, 8, 10, and 12) and absence (lanes 5, 7, 9, and 11) of T3 (1 $\mu \mathrm{M}$ ). Inputs (lanes 1 and 2) were 10\% of that used in the binding experiments (lanes 5-12). The binding site of PTTG1 with TR $\beta 1$ and PV was located in the aminoterminal domain of PTTG1 (lanes 5-12). (E). Schematic representation of full-length and truncated PTTG1 proteins, with boundaries indicated.

mice shown by immunohistochemical staining (Figure 1). After immunoprecipitation of thyroid extracts with anti-TR antibody (J52) that recognizes the common epitope at the A/B domain of TR $\beta 1$ and PV, Western blotting showed that more PTTG1 in the thyroids of TR $\beta^{P V / P V}$ mice bound to PV than to TR $\beta 1$ of wild-type thyroids (Figure 3A, compare lanes 3 and 4). Figure 3A, lane 5, shows the negative control for coimmunoprecipitation in which an irrelevant antibody, MOPC, was used in the immunoprecipitation. The loading control for the input is shown in Figure 3A, lanes 12 and 13 , for the wild-type and $T R \beta^{P V / P V}$ mouse extracts, respectively. On the basis of the band intensities in Figure 3A, lanes 1-4, about $2 \%-4 \%$ of the endogenous PTTG1 was coimmunoprecipitated with TR $\beta 1$ or PV. This is an underestimated value, because dissociation of the complexes was expected to occur as a result of the experimental manipulation. We also found that endogenous PTTG1 was associated with TR $\beta 1$ and PV in HeLa cells stably expressing either Flag-tagged TR $\beta 1$ (FH-TR $\beta 1$ cells) or PV (FH-PV cells) similarly by coimmunoprecipitation analysis (Figure 3A). Using equal amounts of cellular lysates (input controls using $\alpha$-tubulin are shown in Figure 3A, lanes 14 and 15, for FH-TR $\beta 1$ and FH-PV cells, respectively), more PTTG1 was found to associate with PV (lane 9) than with TR $\beta 1$ (lane 8). Figure 3A, lanes 10 and 11, were the negative controls. These results indicate that in vivo, endogenous PTTG1 is bound to TR $\beta 1$ or PV.

To further show that the endogenous PTTG1 interacted with TR $\beta 1$ or PV in another cell type in addition to thyroid and HeLa cells, we carried out coimmunoprecipitation in CV-1 cells cultured in medium with or without T3. As CV-1 cells lack endogenous TRs, cells were therefore transfected with Flag-tagged TR $\beta 1$ (F-TR $\beta 1$ ) or PV (F-PV) expression plasmids. Western blot analysis using antiFlag antibodies indicated that similar levels of F-TR $\beta 1$ and F-PV
(Figure 3B, lanes 1 and 3, respectively) were expressed in the transfected CV-1 cells in the absence of T3. However, in the presence of $\mathrm{T} 3$, we observed a reduced level of F-TR $\beta 1$ (Figure 3B, compare lanes 1 and 2), but not of F-PV (compare lanes 3 and 4). These findings are consistent with our previous study in which the T3-induced degradation of TR $\beta 1$ was detected (24). Using the anti-TR $\beta 1$ antibody C4 for immunoprecipitation followed by Western blot analysis using anti-PTTG1 antibody, we found that endogenous PTTG1 was associated with TR $\beta 1$ in the presence and absence of T3 (Figure 3B, lanes 7 and 8). Similarly, using the PV-specific antibody 302, we also found endogenous PTTG1 to associate with PV in the absence and presence of T3 (Figure 3B, lanes 11 and 12, respectively). Figure $3 \mathrm{~B}$, lanes 5, 6, 9, and 10, show the endogenous PTTG1 from the direct Western blot analysis of total cellular lysates. A lower level of endogenous PTTG1 was consistently observed in TR $\beta 1$-transfected cells in the presence of T3 compared with in the absence of T3 (Figure $3 \mathrm{~B}$, compare lanes 5 and 6 ). No such $\mathrm{T} 3$-induced reduction was noted in cells transfected with PV (Figure 3B, compare lanes 9 and 10). Analysis of the band intensities in Figure 3B, lanes 5-12, indicated that about $3 \%-5 \%$ of the endogenous PTTG1 was associated with TR $\beta 1$ or PV. These values, however, represent the minimal amounts compared with those in vivo, as under the experimental conditions some dissociation of the PTTG1/TR $\beta 1$ or PTTG1/PV complexes was certain to occur.

The interaction of endogenous PTTG1 with TR $\beta 1$ or PV was further confirmed in CV-1 cells using confocal microscopy (Figure 4). The transfected F-TR $\beta 1$ (Figure 4, A and E) or F-PV (Figure 4, I and $\mathrm{M}$ ) and the endogenous PTTG1 (Figure 4, B, F, J, and N) were visualized in interphase cells using Alexa Fluor 488 (TR $\beta 1$ and PV; green) and Texas Red (PTTG1; red), respectively. The subcellular distribution of TR $\beta 1$ (Figure 4, compare A and E) and PV (Figure 
A Thyroid and HeLa cells

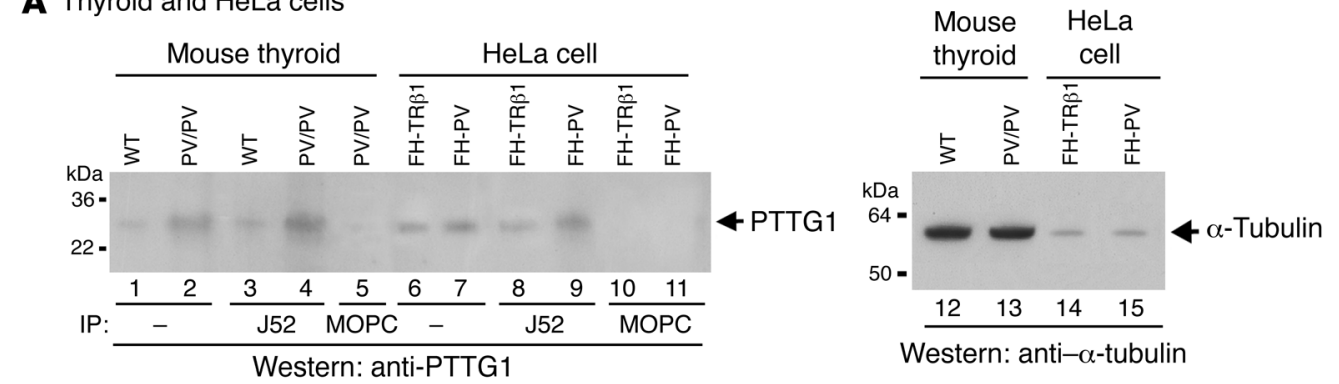

B CV-1 cells
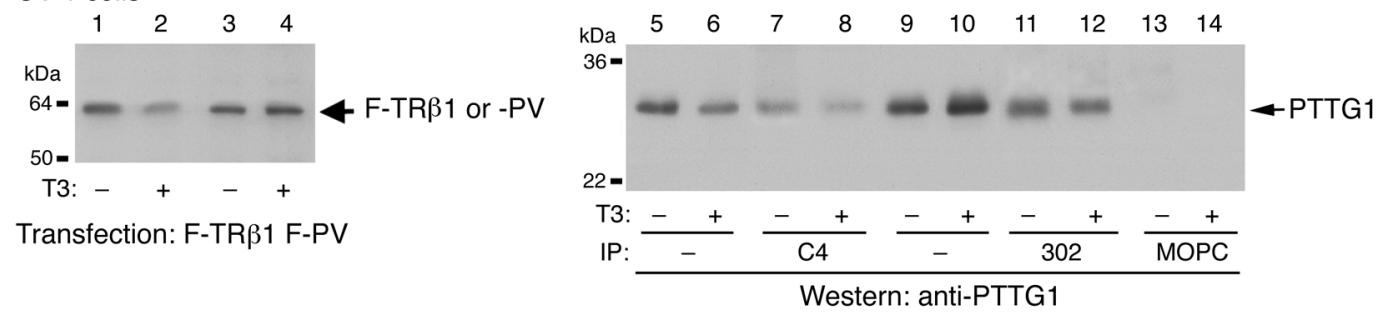

Figure 3

Association of endogenous PTTG1 with TR $\beta 1$ or PV in thyroid and cultured cells. (A) Coimmunoprecipitation of extracts prepared from thyroids of wild-type or TR $\beta^{P V I P V}$ mice and FH-TR $\beta 1$ or FH-PV cells was performed as described in Methods. Cell lysates were first immunoprecipitated with anti-TR/PV antibody J52 (lanes 3, 4, 8, and 9) or the control antibody MOPC (lanes 5, 10, and 11) followed by Western blot analysis using anti-PTTG1 antibody. Lanes 12-15 show the corresponding loading controls using $\alpha$-tubulin. (B) CV-1 cells were transfected with expression plasmid of F-TR $\beta 1$ (lanes 1, 2, and 5-8) or F-PV (lanes 3, 4, and 9-14) at $8 \mu \mathrm{g}$ each. Lanes 1-4 show the expressed F-TR $\beta 1$ and F-PV protein by direct Western blot analysis using anti-Flag antibody $(0.5 \mu \mathrm{g} / \mathrm{ml})$. For coimmunoprecipitation, cell lysates were immunoprecipitated with monoclonal anti-TR $\beta 1$ antibody (C4; lanes 7 and 8) or anti-PV antibody (302; lanes 11 and 12) with and without T3 followed by Western blot analysis with polyclonal rabbit anti-PTTG1 antibody. Inputs are shown in lanes 5, 6, 9, and 10.

4, compare I and M) was mainly nuclear. Figure 4, B, F, J, and N, show that PTTG1 was mainly concentrated in the nucleus, but cytoplasmic PTTG1 was also apparent. When the F-TR $\beta 1$ or F-PV and PTTG1 images were merged, colocalization of endogenous PTTG1 with either TR $\beta 1$ or PV was clearly observed in the nuclei, as shown by the yellow areas (Figure 4, C, G, K, and O). It is important to note that under the same experimental conditions, significantly lower TR $\beta 1$ signals (Figure 4E), PTTG1 signals (Figure 4F), and merged signals (Figure 4G) were observed in cells treated with T3. To visualize the colocalization of PTTG1 with TR $\beta 1$ or PV in the cells at the prometaphase/metaphase, we treated the cells with thymidine/nocodazole in the absence of T3 and then released the cells in T3-deficient growth media for 6 hours (Figure 4, Q-X). In cells at the prometaphase/metaphase, PTTG1 was colocalized with TR $\beta 1$ (Figure 4T) and with PV (Figure 4X). Taken together, these data confirmed that, consistent with the in vitro GST pull-down study and coimmunoprecipitation assays in cells (Figure 2), PTTG1 associates with TR $\beta 1$ and PV, and they colocalize in the nucleus.

The association of PTTG1 with TR $\beta 1$ or PV was also demonstrated in cells using mammalian 2-hybrid assays (Figure 4Y). GAL4 is a DNA-binding transcription factor required for the activation of the GAL genes in response to galactose. When PTTG1 was fused to the DNA-binding domain of GAL4 (GAL4-PTTG1) and cotransfected with an expression vector for TR $\beta 1$ in the presence of upstream activating sequence-luciferase reporter (UAS-luciferase reporter), the unliganded TR $\beta 1$ repressed the basal transcription activity (Figure 4Y). In the presence of T3, a 2-fold increase in transcription activation was observed. Cotransfection of an expression plasmid for PV also mediated the repression of basal transcription activity. However, since PV does not bind T3, no transcription activation was detected. These findings not only demonstrate the association of PTTG1 with TR $\beta 1$ and PV in cells, but also indicate that TR $\beta 1$ and PV maintain a similar responsiveness to hormone while associated with DNA-bound PTTG1.

T3-dependent, TR $\beta 1$-mediated destabilization of PTTG1 occurs via the proteasomal degradation machinery. We have previously shown that the T3-induced degradation of TR $\beta 1$ is mediated by the proteasome degradation pathway and that $\mathrm{TR} \alpha 2$, which does not bind T3, fails to be degraded (24). Furthermore, it has also been reported that treatment of cells with LLnL (a proteasome inhibitor) increases PTTG1 levels, indicating that PTTG1 is degraded through the proteasome pathway (20). The present finding that PTTG1 was associated with TR $\beta 1$ raised the possibility that this interaction could facilitate the degradation of PTTG1 via the proteasome degradation pathway. To test this hypothesis, we first determined whether $\mathrm{T} 3$ in the absence of its receptor TR $\beta 1$ affected the proteasomemediated degradation of PTTG1 in CV-1 cells (Figure 5A). Cells were transfected with F-PTTG1 and F-TR $\beta 1$ or F-PV expression vectors. As shown by Western blot analysis using anti-Flag antibodies, Figure 5A, lanes 1 and 2, demonstrate that T3 had no effect on the abundance of F-PTTG1 in the absence of F-TR $\beta 1$. In the presence of the proteasome-specific inhibitor MG132, F-PTTG1 levels were significantly increased independent of T3 (Figure 5A, lanes 3 and 4), further supporting that F-PTTG1 is degraded via the proteasome degradation pathway.

In the presence of T3 and F-TR $\beta 1$, a different picture emerged. Concomitant with the T3-induced degradation of F-TR $\beta 1$ (Figure 5A, lane 6), F-PTTG1 was degraded (compare lane 6 with lanes 1, 2, and 5). When the proteasome degradation of F-TR $\beta 1$ was blocked by MG132, F-PTTG1 remained high (Figure 5A, lane 8) similar to 


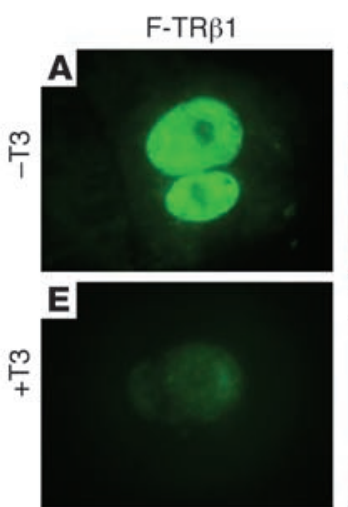

F-PV
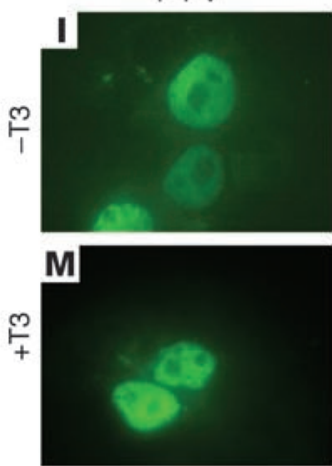

F-TR $\beta 1$

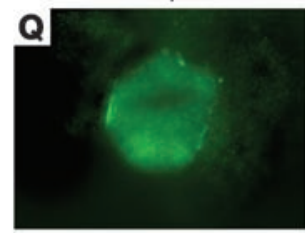

F-PV

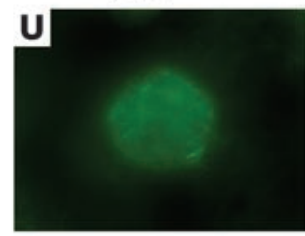

$r$

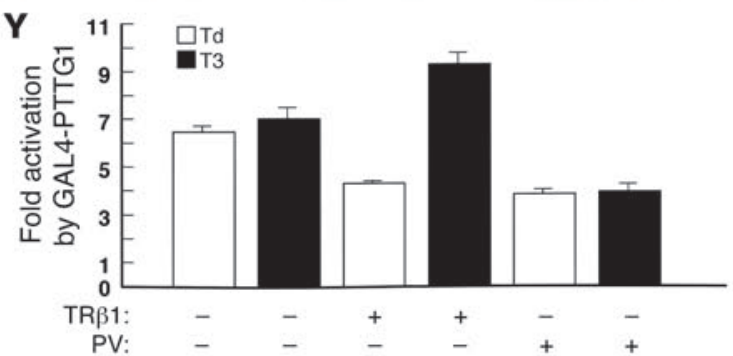

Merged
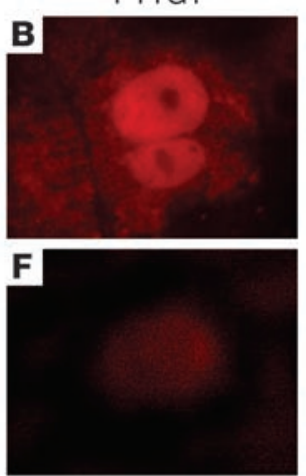

PTTG1
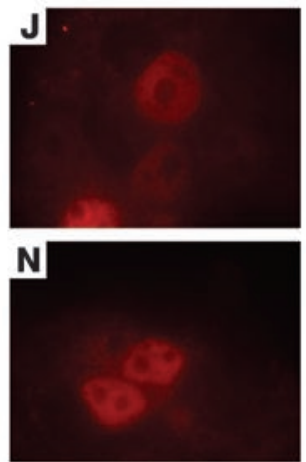

PTTG1

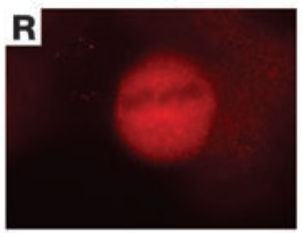

PTTG1
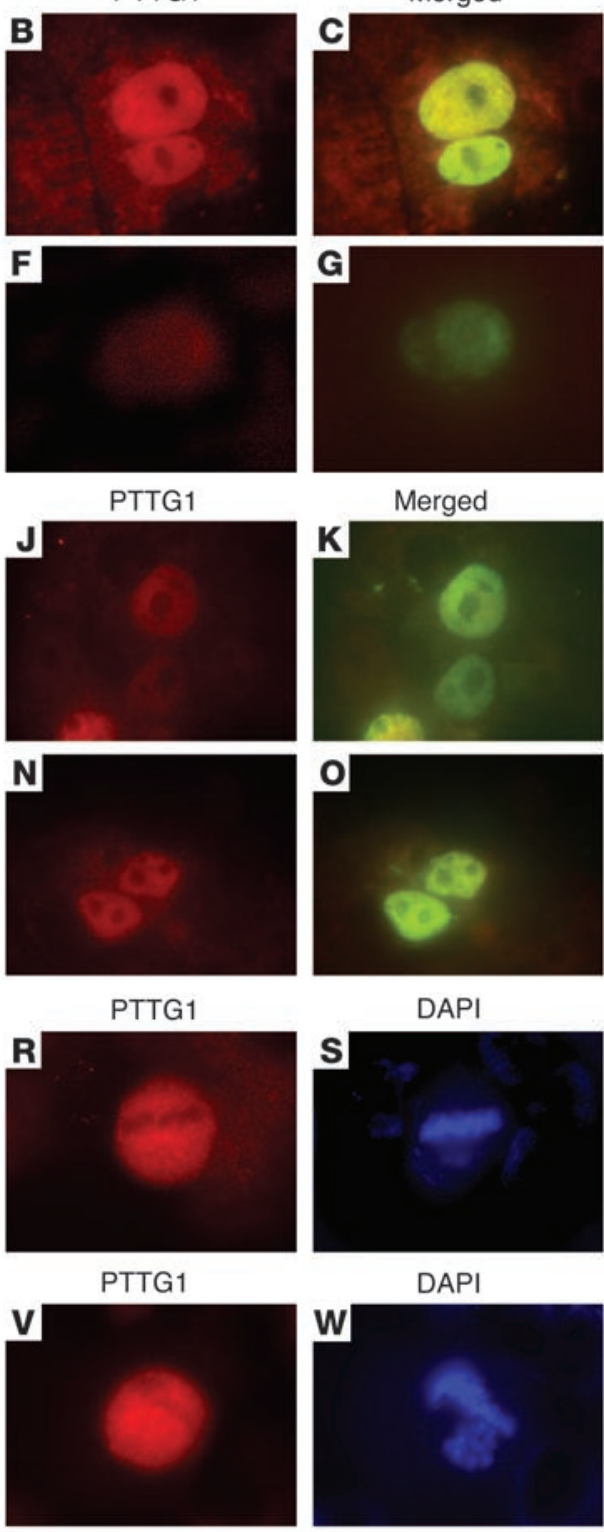

Merged

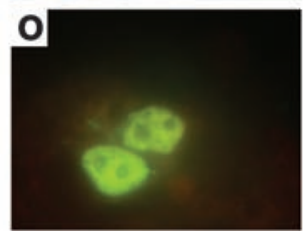

DAPI

DAPI
DAPI
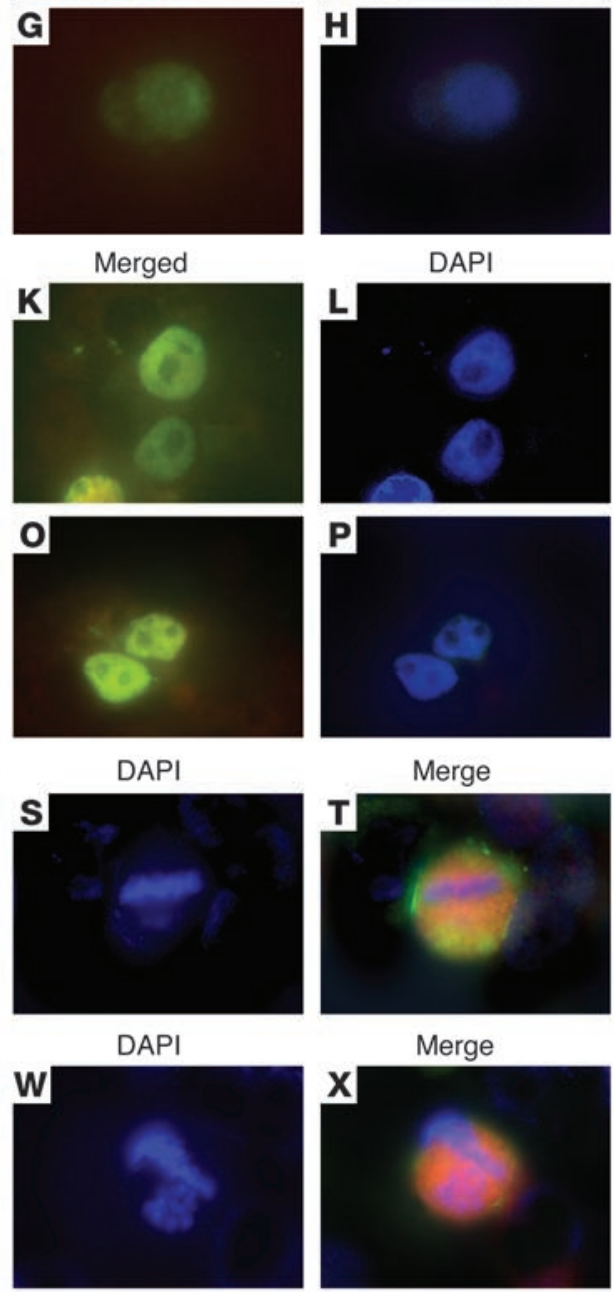
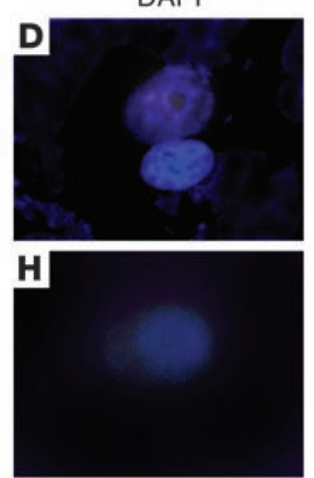

DAPI
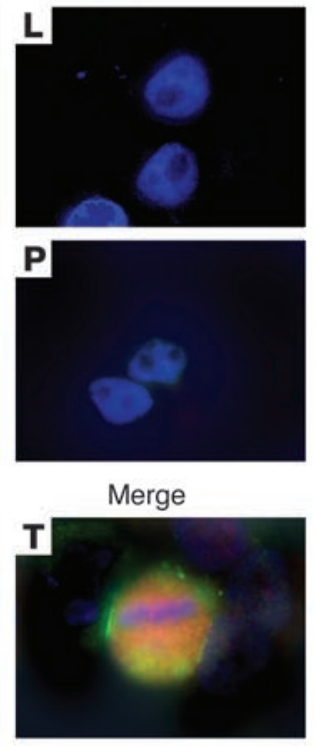

X
Figure 4

Colocalization of PTTG1 with TR $\beta 1$ or PV by confocal microscopy. (A-P) CV-1 cells $\left(1-1.3 \times 10^{5}\right)$ were transfected with expression plasmids F-TR $\beta 1$ or F-PV and cultured in the absence (A-D and $\mathbf{I}-\mathbf{L}$ ) or presence (E-H and $\mathbf{M}-\mathbf{P})$ of T3. Endogenous PTTG1 (B, F, J, and N; red) and the transfected F-TR $\beta 1$ (A and $\mathbf{E}$; green) and F-PV (I and $\mathbf{M}$; green) were visualized in cells at the interphase by fluorescence microscopy using antiFlag antibody for F-TR $\beta 1$ and F-PV and anti-PTTG1 antibody for endogenous PTTG1. D, H, L, and $\mathbf{P}$ were stained with DAPI. Merged images are shown in $\mathbf{C}, \mathbf{G}, \mathbf{K}$, and $\mathbf{O}$. (Q-X) Colocalization of the endogenous PTTG1 with F-TR $\beta 1$ in $\mathrm{FH}-\mathrm{TR} \beta 1$ cells $(\mathbf{Q}-\mathbf{T})$ or $\mathrm{F}-\mathrm{PV}$ in $\mathrm{FH}-\mathrm{PV}$ cells $(\mathbf{U}-\mathbf{X})$ in the absence of T3 at the prometaphase/metaphase. Merged images are shown in $\mathbf{T}$ and $\mathbf{X}$. Magnification, $\times 160$. (Y) Interaction of PTTG1 with TR $\beta 1$ determined by PTTG1-GAL4/UAS reporter system. The Gal4 report system is described in Methods. CV-1 cells were cotransfected with the expression plasmids of PTTG1-GAL4, UAS-luciferase reporter, and TR $\beta 1$ or $\mathrm{PV}$ (with or without $100 \mathrm{nM} \mathrm{T3}$ ), and luciferase activity was determined. Data are mean \pm SE $(n=3)$. Td, T3 deficient. the level when TR $\beta 1$ was unliganded (lane 7) and to that without F-TR $\beta 1$ (lanes 3 and 4). These results suggest that the liganded TR $\beta 1$ facilitated the degradation of F-PTTG1 via the proteasome degradation pathway. Moreover, the T3-induced, TR $\beta 1$-mediated degradation of the endogenous PTTG1 was also demonstrated by Western blot analysis using anti-PTTG1 antibodies (Figure 5B, compare lanes 5 and 6 ). Figure $5 \mathrm{C}$ shows the corresponding loading control using $\alpha$-tubulin.
The above observations would predict that PV, which does not bind T3 (4), will not undergo proteasome-mediated degradation and thus will not facilitate PTTG1 degradation. Indeed, concomitant with the stability of PV, the high level of PV protein in the presence of $\mathrm{T} 3$ was similar to that without T3 (Figure 5D, compare lanes 5 and 6). Figure 5D, lanes 7 and 8, further show additional stabilization of PTTG1 in the presence of MG132, suggesting that the stabilization of PTTG1 observed in lane 6 was not due to 

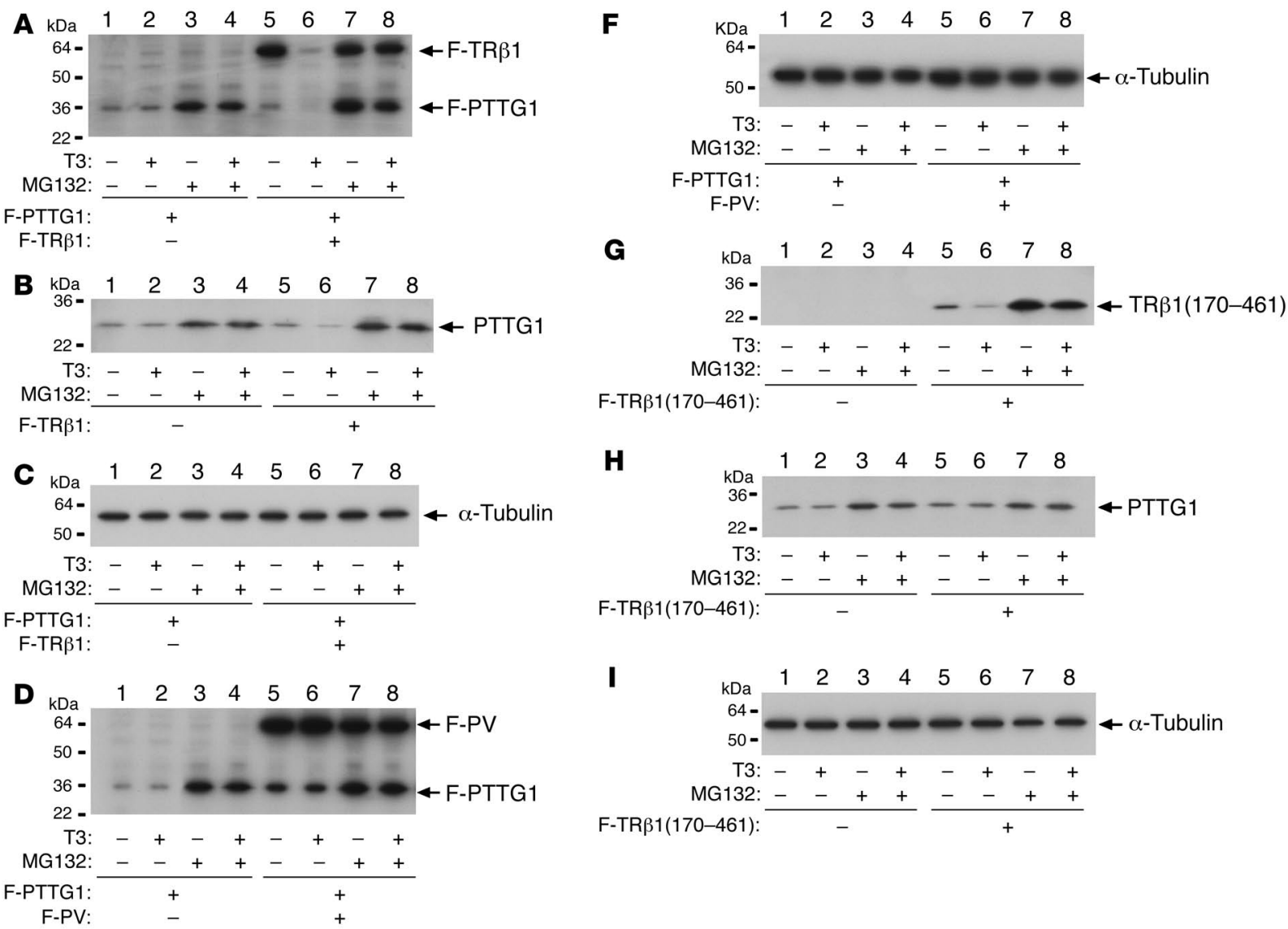

F-TRP1(170-461):

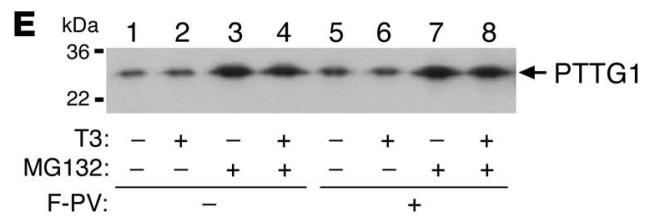

\section{Figure 5}

Regulation of PTTG1 stability by the T3-bound TR $\beta 1$ via the proteasome-mediated pathway. CV-1 cells were cotransfected with expression plasmids of F-PTTG1 along with F-TR $\beta 1$ (A-C), F-PV (D-F), and F-TR $\beta 1(170-461)(\mathbf{G}-\mathbf{I})$ in the absence or presence of T3 (100 nM) and with or without MG132 as described in Methods. Antibodies used for Western blot analysis were anti-Flag (0.5 $\mu \mathrm{g} / \mathrm{ml})$, anti-PTTG1 (1:250 dilution), and anti- $\alpha$-tubulin for loading controls (1:6,000 dilution).

the loss of function of the 20S core proteasome. In addition, the endogenous PTTG1 was also stabilized by the presence of PV using anti-PTTG1 antibodies (Figure 5E, lanes 5 and 6). The corresponding loading control using $\alpha$-tubulin is shown in Figure 5F.

The GST pull-down assays showed that the interacting domain of TR $\beta 1$ with PTTG1 was localized in the DNA-binding domain (Figure $2 \mathrm{~B}$ ). This would predict that if the DNA-binding domain of $\operatorname{TR} \beta 1$ were deleted, the truncated TR $\beta 1$ lacking the DNA-binding domain but retaining the ligand-binding domain [TR $\beta 1(170-461)]$ would undergo T3-induced degradation, but since PTTG1 could no longer interact with TR $\beta 1$, PTTG1 would not be degraded. Indeed, when $\mathrm{CV}-1$ cells were transfected with the expression plasmid for F-TR $\beta 1(170-461)$ and either treated with T3 or left untreated, Western blot analysis with anti-Flag antibodies showed that the truncated F-TR $\beta 1(170-461)$ underwent T3-induced degradation (Figure 5G, compare lanes 5 and 6). However, the endogenous PTTG1 was not degraded in the presence of F-TR $\beta 1(170-461)$ (Figure 5H, compare lanes 5 and 6). The endogenous PTTG1 level was similar to that observed in the absence of transfected F-TR $\beta 1(170-461)$ (Figure $5 \mathrm{H}$, compare lanes 1 and 2 with lanes 5 and 6). In the presence of proteasome inhibitor MG132, the endogenous PTTG1 was elevated, as expected (Figure 5H, lanes 7 and 8), indicating that the stability of PTTG1 observed in lanes 5 and 6 was not due to direct impairment of the proteasome system. Figure 5I shows the corresponding loading control using $\alpha$-tubulin. Taken together, these findings indicate that the cellular stability of PTTG1 is regulated by the liganded TR $\beta 1$, but not by PV, which does not bind T3, resulting in the aberrant accumulation of cellular PTTG1.

Differential recruitment of PA28 $\gamma$ by TR $\beta 1 / P T T G 1$ and PV/PTTG1 complexes. To understand how PV failed to regulate the stability of PTTG1 as the liganded TR $\beta 1 \mathrm{did}$, we considered the possibility that the liganded TR $\beta 1 / \mathrm{PTTG} 1$ and PV/PTTG1 complexes recruit 

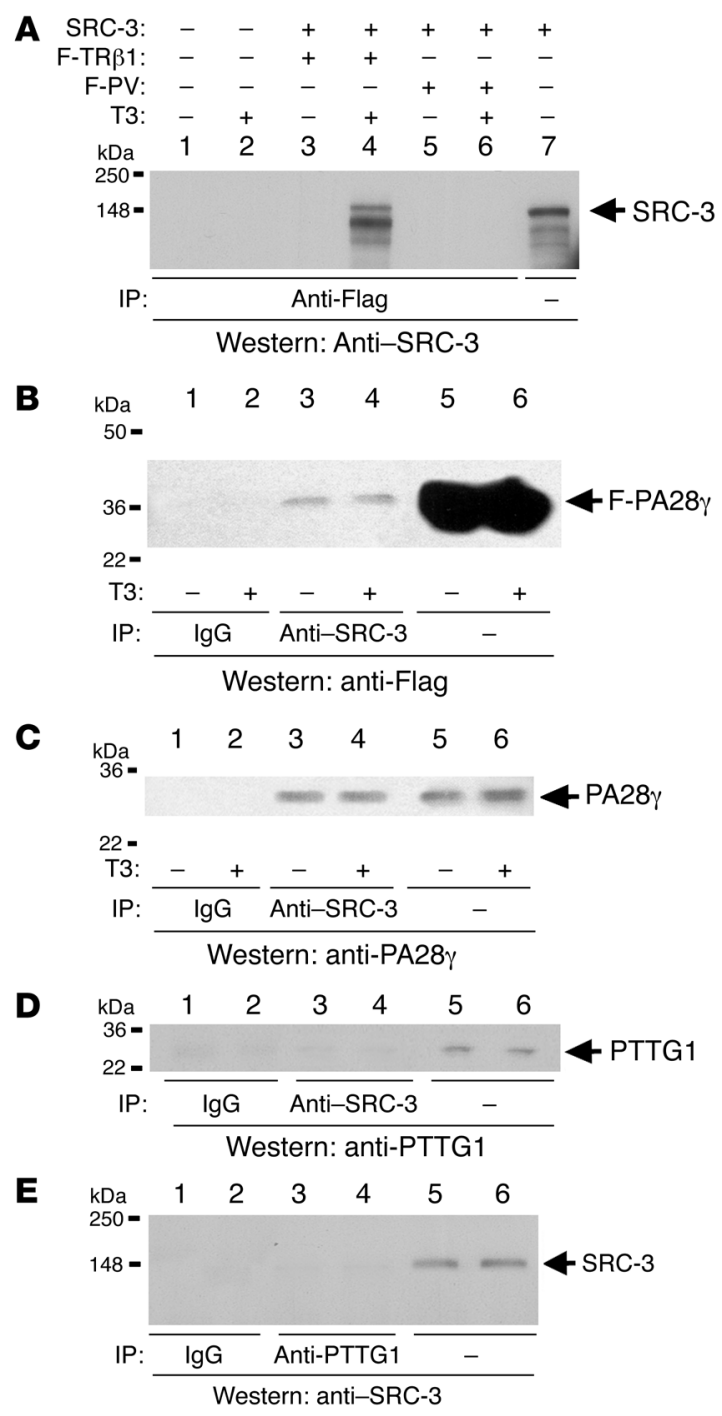

proteasome activators differently. Recent reports have suggested that SRC-3 is physically associated with PA28 $\gamma$, an activator of the trypsin-like activity of the proteasome $(23,25)$, and that this interaction results in the increased degradation of SRC-3 via $11 \mathrm{~S}$ proteasome in an ubiquitin- and ATP-independent manner (23). Similar to other steroid hormone receptors (26), the liganded TR $\beta 1$ recruited SRC- 3 in cells, but the unliganded TR $\beta 1$ did not (Figure 6A, lanes 3 and 4). PV, which does not bind T3, did not bind SRC-3 whether T3 was present or not (Figure 6A, lanes 5 and 6). Consistent with the report by Li et al. (23), we found that SRC-3 was associated with the transfected F-PA28 $\gamma$ (Figure 6B, lanes 3 and 4) as well as the endogenous PA28 (Figure 6C, lanes 3 and 4). In the presence of TR $\beta 1$, the interaction of SRC-3 with F-PA28 $\gamma$ or the endogenous PA28 $\gamma$ (Figure 6, B and C, compare lanes 3 and 4) was not affected whether T3 was present or not. We sought to determine whether SRC-3 interacted with the endogenous PTTG1 by coimmunoprecipitation using the anti-SRC-3 antibody (Figure 6D) or the anti-PTTG1 antibody (Figure 6E) followed by Western blot analysis using anti-PTTG1 or anti-SRC-3 antibodies, respectively. In cells without TR $\beta 1$, no discernible signals were observed that would indicate the direct interaction of endogenous PTTG1 with SRC-3. GST pull-down assays also failed to show the direct

\section{Figure 6}

Recruitment of SRC-3 and PA28 $\gamma$ by T3-bound TR $\beta 1$ in cells. (A) SRC-3 was recruited by T3-bound TR $\beta 1$. Kidney HEK293 cells were cotransfected with expression plasmids of SRC-3 and F-TR $\beta 1$ (lanes 3 and 4) or F-PV (lanes 5 and 6) and were treated either with T3 (lanes 4 and 6; $100 \mathrm{nM}$ ) or without T3 (lanes 3 and 5). Immunoprecipitation was performed using anti-Flag antibody followed by Western blot analysis with anti-SRC-3 antibodies. Lanes 1 and 2 were negative controls in which cells were not transfected with expression plasmids for F-TR $\beta 1$ or F-PV. Lane 7 shows the positive control for SRC-3 by direct Western blot analysis. (B and C) FH-TR $\beta 1$ cells were transfected with (B) or without (C) expression plasmids of F-PA28 $\gamma$, and cells were treated either with (lanes 2, 4, and 6) or without (lanes 1, 3, and 5) 100 nM T3. Coimmunoprecipitation was performed using anti-SRC-3 antibody followed by Western blot analysis using anti-Flag (B) or antiPA28 $\gamma$ antibody (C). (D and E) Endogenous PTTG1 and SRC-3 do not interact. Coimmunoprecipitation was performed using CV-1 cell lysate and anti-SRC-3 antibody in duplicates (D; lanes 3 and 4), anti-PTTG1 antibody (E; lanes 3 and 4 ), or $\lg G$ as negative control (D and $\mathbf{E}$; lanes 1 and 2) followed by Western blot analysis using anti-PTTG1 antibody (D) or anti-SRC-3 antibody (E). Lanes 5 and 6 in $\mathbf{D}$ and $\mathbf{E}$ are positive controls from direct Western blot analysis.

interaction of SRC-3 with PTTG1 (data not shown). Therefore, SRC-3 does not directly bind to PTTG1 in cells. Thus, the binding of T3 to TR $\beta 1$ allows the liganded TR $\beta 1$, but not PV, to recruit SRC-3/PA28 $\gamma$ and subsequently activate the degradation of the liganded TR $\beta 1$ as well as PTTG1 (see Discussion).

This model predicts that a reduced protein level of PA28 $\gamma$ would favor the stability of PTTG1. Indeed, when the PA28 $\gamma$ protein level was lowered ( $90 \%$ reduction compared with control) by siRNA (Figure 7A, compare lanes 2 and 3 with lanes 4 and 5), no T3induced, TR $\beta 1$-mediated degradation of the endogenous PTTG1 was detected (Figure 7B, compare lanes 4 and 5). This was in contrast to cells treated with control siRNA, in which $\mathrm{T} 3$ treatment led to the degradation of PTTG1 (Figure 7B, compare lanes 2 and 3). The PTTG1 level in siRNA-treated cells in the presence of T3 was similar to that in cells treated with control siRNA in the absence of T3 (Figure 7B, compare lanes 2 and 5). The corresponding loading controls are shown in Figure $7 \mathrm{C}$. These results further support the activating role of SRC-3/PA28 $\gamma$ complexes in the regulation of the stability of PTTG1 by TR $\beta 1$.

The findings from the above cell-based experiments predicted that in mice deficient in SRC-3 (SRC-3/-- mice), PTTG1 abundance in the thyroid would be higher compared with wild-type mice. Indeed, Western blot analysis showed that PTTG1 abundance in vivo was significantly higher than that in the wild-type mice (2.1fold higher; $P<0.05$; Figure 8A). Figure 8C shows the corresponding loading controls using $\alpha$-tubulin. Consistent with our results from immunohistochemical analysis (Figure 1D), we found that PTTG1 abundance in the thyroid of $T R \beta^{P V / P V}$ mice was 4.7 -fold higher than that in wild-type mice (Figure 8B, compare lanes 1 and 2 with lanes $3-5)$. However, the increased PTTG1 abundance was not altered in $T R \beta^{P V / P V}$ mice deficient in SRC-3 (Figure 8B), since PV was shown not to bind SRC-3 (Figure 6A), and therefore PTTG1 abundance was not expected to be affected by the lack of SRC-3. Figure 8D shows the corresponding loading controls for the Western blot in Figure $8 \mathrm{~B}$. Taken together, these in vivo findings clearly support an important role of SRC-3 in modulating the stability of PTTG1 in vivo.

Aberrant accumulation of PTTG1 levels induced by PV impedes cell cycle progression. PTTG1 is a mammalian securin functioning to hold 

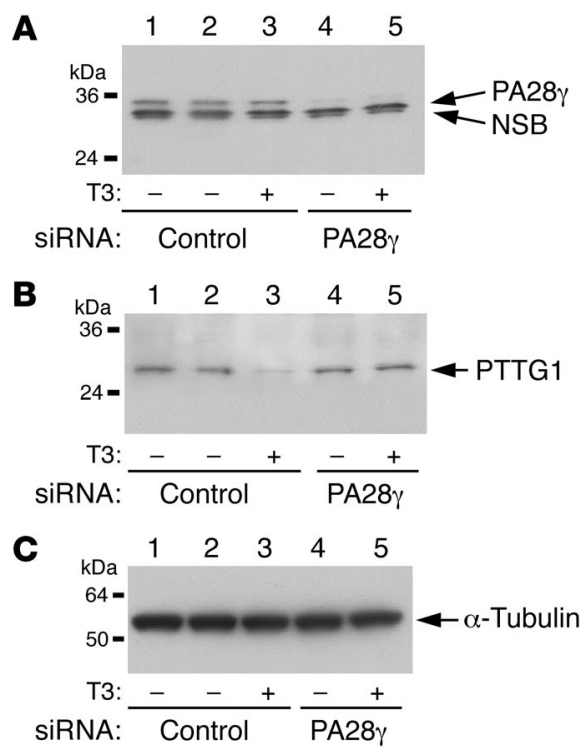

sister chromatids together during mitosis, and its overexpression has been shown to cause aneuploidy $(13,20-22,27)$. To evaluate the functional consequences of $\mathrm{PV}$-induced accumulated cellular PTTG1, we first determined the cell cycle-dependent expression of endogenous PTTG1. FH-TR $\beta 1$ and FH-PV cells were each arrested at the $G_{0} / G_{1}, S$, and $G_{2} / M$ phases and the protein abundance of PTTG1, F-TR $\beta 1$, F-PV, and the cell cycle markers (cyclin D1, cyclin $A$, and cyclin $B 1$ for $G_{0} / G_{1}, S$, and $G_{2} / M$ phases, respectively) were determined at each cell cycle by Western blot analysis (Figure 9A). The PTTG1 level was weak but detectable at the $\mathrm{G}_{0} / \mathrm{G}_{1}$ phase, began to increase at the $\mathrm{S}$ phase, and reached its peak at the $\mathrm{G}_{2} / \mathrm{M}$ phase. Consistent with previous reports by others (28), a phosphorylated PTTG1 (p-PTTG1) with a slower migration in the SDS gel was observed at the $\mathrm{G}_{2} / \mathrm{M}$ phase. These cell cycle-dependent patterns of PTTG1 were similar to those previously observed $(28,29)$. TR $\beta 1$ and PV had cell cycle-dependent profiles that were different from that of PTTG1 in that they were expressed at all cell cycles, but with the lowest abundance at the $\mathrm{S}$ phase.

We further analyzed at what phase of the cell cycle was endogenous PTTG1 associated with TR $\beta 1$ and PV by coimmunoprecipi-

\section{Figure 7}

Stabilization of endogenous PTTG1 by siRNA knockdown of PA28 $\gamma$ expression in cells. CV-1 cells were cotransfected with a control siRNA (lanes 1-3) or PA28 (lanes 4 and 5), with (lanes 2-5) or without (lane 1, control) the expression plasmid of TR $\beta 1$. Cells were treated with (lanes 3 and 5) or without (lanes 1, 2, or 4) $100 \mathrm{nM}$ T3. Endogenous PA28 $\gamma$ (A) or PTTG1 (B) protein levels were detected by Western blot analysis using anti-PA28 $\gamma$ or anti-PTTG1 antibodies. "NSB" in A indicates a nonspecific band migrating slightly faster than PA28 $\gamma$ (23). (C) Corresponding loading controls using $\alpha$-tubulin.

tation (Figure 9B). The association of the endogenous PTTG1 with either F-TR $\beta 1$ or F-PV occurred mainly at the $\mathrm{G}_{2} / \mathrm{M}$ phase (Figure $9 \mathrm{~B}$, lanes 4 and 8 ), but weak associations were also detected in the $\mathrm{G}_{0} / \mathrm{G}_{1}$ (lanes 2 and 6 ) and $\mathrm{S}$ phases (lanes 3 and 7). It is interesting to note that TR $\beta 1$ and PV interacted with PTTG1 as well as p-PTTG1 (Figure 9B, lanes 4 and 8). Compared with the input shown in Figure 9B, lane 10, approximately $6 \%-8 \%$ of endogenous PTTG1 was associated with TR $\beta 1$ or PV in the $\mathrm{G}_{2} / \mathrm{M}$ phase.

The effect of PV-induced aberrant accumulation of PTTG1 on cell cycle progression was analyzed after arresting the FH-TR $\beta 1$ and FH-PV cells at the $\mathrm{G}_{2} / \mathrm{M}$ phase by thymidine/nocodazole block and releasing from the $\mathrm{G}_{2} / \mathrm{M}$ block by culturing in media containing $\mathrm{T} 3$ in FBS. Protein abundance of endogenous PTTG1, F-TR $\beta 1$, F-PV and the $\mathrm{G}_{2} / \mathrm{M}$ phase marker (cyclin B1) was assessed in a time-dependent manner as cells were exiting from the $G_{2} / M$ phase (Figure 10). As FH-TR $\beta 1$ cells were exiting from the $\mathrm{G}_{2} / \mathrm{M}$ phase, PTTG1 continued to decline, and after 8 hours, all p-PTTG1 and most PTTG1 was degraded. In contrast, p-PTTG1 as well as PTTG1 in FH-PV cells remained elevated after 8 hours. The effect of the PV-induced aberrant accumulation of PTTG1 was clearly evident by the marked delay of cells to exit from the $\mathrm{G}_{2} / \mathrm{M}$ phase block (Figure 10). As shown in Figure 10, lanes 3-6, 14.8\%, 60.8\%, 71.6\%, and $74.2 \%$ of FH-TR $\beta 1$ cells had exited the $\mathrm{G}_{2} / \mathrm{M}$ phase to enter into the $\mathrm{G}_{0} / \mathrm{G}_{1}$ and $\mathrm{S}$ phases after $2,4,6$, and 8 hours, respectively. However, markedly lower numbers of FH-PV cells had exited from the $\mathrm{G}_{2} / \mathrm{M}$ phase $(14.8 \%, 30.3 \%, 38.2 \%$, and $53.3 \%$ after $2,4,6$, and 8 hours, respectively; Figure 10, lanes 9-12). The severe delay in exiting from the $\mathrm{G}_{2} / \mathrm{M}$ phase was also shown by the delayed degradation of the $\mathrm{G}_{2} / \mathrm{M}$ phase marker, cyclin B1. These findings are consistent with the observations by Yu et al. in which the mitotic progression was
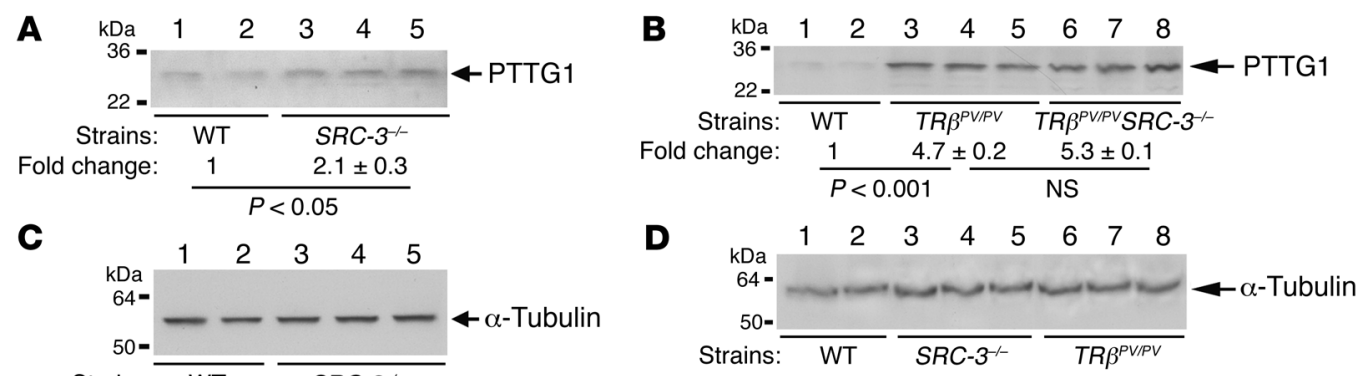

\section{Figure 8}

Comparison of PTTG1 abundance in thyroids of wild-type, $S R C-3^{-/}, T R \beta^{P V / P V} S R C-3^{-/-}$, and TR $\beta^{P V / P V} S R C-3^{+/+}$mice. Protein lysates $(50 \mu \mathrm{g})$ from thyroids of 2 wild-type (lanes 1 and 2 ) and $3 S R C-3^{-/-}$mice (lanes 3-5) were separated by gel electrophoresis. Western blot analysis was performed with antibody against mouse PTTG1 (A; Ab 77; see Methods) and $\alpha$-tubulin (C) for control of an equal amount of lysates loading onto the gel. (B) Similar Western blot analyses were performed in the thyroid lysates of 2 wild-type mice (lanes $1-2$ ), 3 TR $\beta^{P V / P V} S R C-3^{+/+}$mice (lanes 3-5), and 3 TR $\beta^{P V / P V} S R C-3^{-/-}$mice (lanes 6-8). NS, not significant. (D) Corresponding loading control using $\alpha$-tubulin. The band intensity was scanned and quantified using NIH Image (http://rsb.info.nih.gov/nih-image/), and data are expressed as mean \pm SD $(n=2-3)$. 


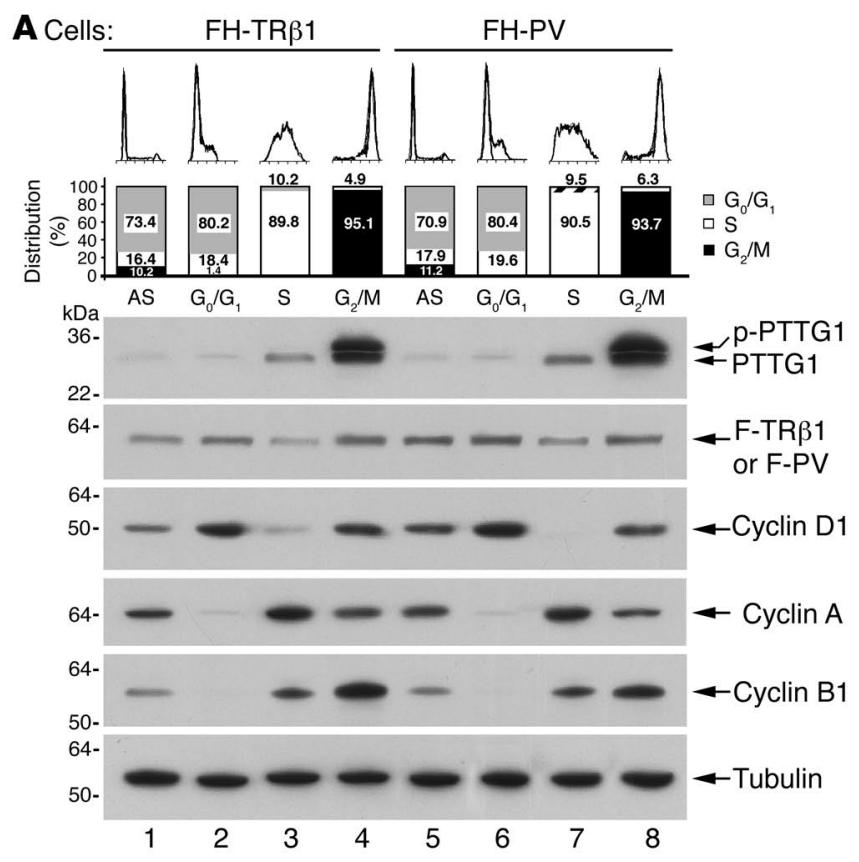

B

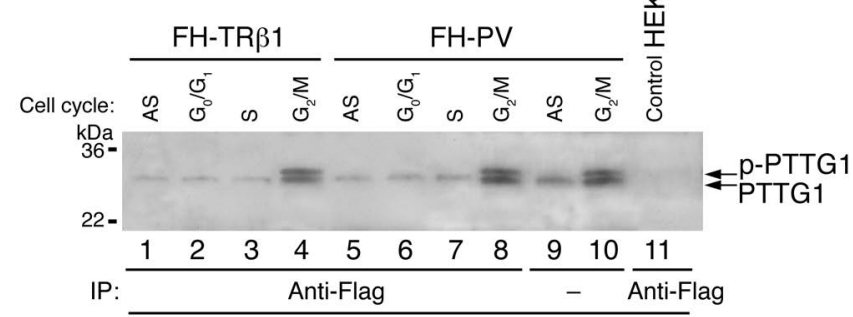

Western: Anti-PTTG1

severely inhibited by overexpressed PTTG1 (21). A similar mitotic delay in FH-TR $\beta 1$ cells exiting from the $\mathrm{G}_{2} / \mathrm{M}$ phase was observed in the absence of T3: $57.6 \%$ and $61.5 \%$ of cells exited from the $\mathrm{G}_{2} / \mathrm{M}$ phase after 6 and 8 hours, respectively, compared with $71 \%$ and $78 \%$ for T3-treated cells (data not shown).

As cells were exiting from the $\mathrm{G}_{2} / \mathrm{M}$ phase in the presence of T3- and serum-containing growth media, TR $\beta 1$ abundance continued to increase in a time-dependent manner. The different cell cycle-dependent protein profiles between PTTG1 and TR $\beta 1$ suggest that TR $\beta 1$ has other cellular functions in addition to the regulation of the stability of PTTG1. These observations suggest that the regulation in the expression of TR $\beta 1$ differs from that of PTTG1.

\section{Discussion}

Overexpression of PTTG1 has been implicated in the development and progression of many human cancers including thyroid cancers (16). Although the precise mechanisms by which PTTG1 induces cancers have yet to be fully elucidated, one prevailing hypothesis has been that aberrantly increased levels of PTTG1 perturb the normal progression of mitosis (20-22). PTTG1 is a securin, and its association with separin (a protease) prevents the proteolytic activity of separin from acting on cohesions that hold the sister chromatids together before entering the anaphase (27). The timely degradation of securin by proteasome-mediated pathways frees the separin to proteolyze cohesins for proper separation of sister chromatids at the anaphase.

\section{Figure 9}

Protein abundance $(\mathbf{A})$ and interaction $(\mathrm{B})$ of PTTG1, TR $\beta 1$, and PV at different cell cycles. (A) FH-TR $\beta 1$ and $F H-P V$ cells were synchronized in the $G_{0} / G_{1}, S$, and $G_{2} / M$ phases as described in Methods. Asynchronized cells (AS) and synchronized cells at different phases of the cell cycle were confirmed by fluorescence-activated cell sorting analysis, and the expression of cell cycle markers (cyclin D1, cyclin A, and cyclin $B 1$ for the $G_{0} / G_{1}, S$, and $G_{2} / M$ phases, respectively) was determined. The protein abundance of cyclin D1, cyclin A, and cyclin B1 were determined by Western blot analysis using anti-cyclin D1 (1:1,000 dilution), anti-cyclin $\mathrm{A}$ (1:1,000 dilution), and anti-cyclin B1 (1:2,000 dilution) antibodies, respectively. The protein abundance of PTTG1, F-TR $\beta 1$, F-PV, and the loading control $\alpha$-tubulin was determined by Western blot analysis similar to that in Figure 5. (B). Cell lysates $(1 \mathrm{mg})$ prepared from FH-TR $\beta 1$ cells (lanes 1-4) and FH-PV cells (lanes 5-10) not synchronized (lanes 1,5 , and 9 ) or synchronized at the $G_{0} / G_{1}$, $\mathrm{S}$ and $\mathrm{G}_{2} / \mathrm{M}$ phase (lanes 2-4, 6-8, and 10) were analyzed for the interaction of the endogenous PTTG1 with F-TR $\beta 1$ or F-PV by coimmunoprecipitation. Cell lysates were first immunoprecipitated with antiFlag antibodies followed by Western blot analysis with anti-PTTG1. Lane 11 is the negative control using HEK293 cells that did not have TRs. Lanes 9 and 10 show the direct Western blot analysis using antiPTTG1 antibodies, indicating the input ( $25 \mu \mathrm{g}$ of cell lysates).

Thus, abnormally elevated PTTG1 disrupts proper separation of sister chromatids, resulting in aneuploidy $(13,27)$. A strong correlation of the overexpressed PTTG1 with genetic instability has recently been demonstrated not only in a thyroid cancer mouse model (TR $\beta^{P V / P V}$ mice) (12), but also in human thyroid cancers (22).

While the accumulated evidence has supported the linking of mitotic abnormalities to overexpressed PTTG1, very little is known about the underlying mechanisms that lead to aberrantly increased PTTG1 levels. The present study has uncovered what we believe to be a novel mechanism by which PTTG1 becomes resistant to proteasomal degradation via binding to a mutant TR $\beta 1$. On the basis of in vitro binding, cell-based, and in vivo analyses we propose the molecular model shown in Figure 11. PTTG1 physically associates with TR $\beta 1$, and its degradation is facilitated by T3-dependent recruitment of SRC-3/PA28 $\gamma$ complexes. The degradation of PTTG1 frees the separin to proteolyze cohesions to facilitate normal separation of sister chromatids during anaphase (Figure 11A). The unliganded TR $\beta 1$, as well as PV (which does not bind T3), cannot recruit the SRC-3/PA28 $\gamma$ complexes to activate the proteasome degradation; therefore, the PV/PTTG1 complex remains stable, as shown by the persistently elevated PTTG1 and PV (Figure 11B; see also Figure 10). The failure of timely degradation of PTTG1 severely inhibited the proper exit of cells from the $\mathrm{G}_{2} / \mathrm{M}$ phase (Figure 10). The present findings are consistent with the report by Yu et al. (21) in that compared with controls, the metaphase was found to be prolonged ( 7 times longer) by overexpression of PTTG1. Moreover, Yu et al. also showed that overexpression of PTTG1 inhibits chromosome separation and results in asymmetrical cytokinesis (21). We also noted that FH-PV and FH-TR $\beta 1$ cells cultured in T3-deficient media exhibited increased frequency of prometaphase/metaphase mitotic arrest compared with FH-TR $\beta 1$ cells cultured in T3-containing growth media (our unpublished observations). However, the strongest evidence to support that PV-induced aberrantly accumulated PTTG1 led to chromosomal abnormalities came from our previous quantitative spectral karyotyping analysis of 7 PV-expressing thyroid tumor cell lines derived from $T R \beta^{P V / P V}$ mice. The elevated PTTG1 levels 


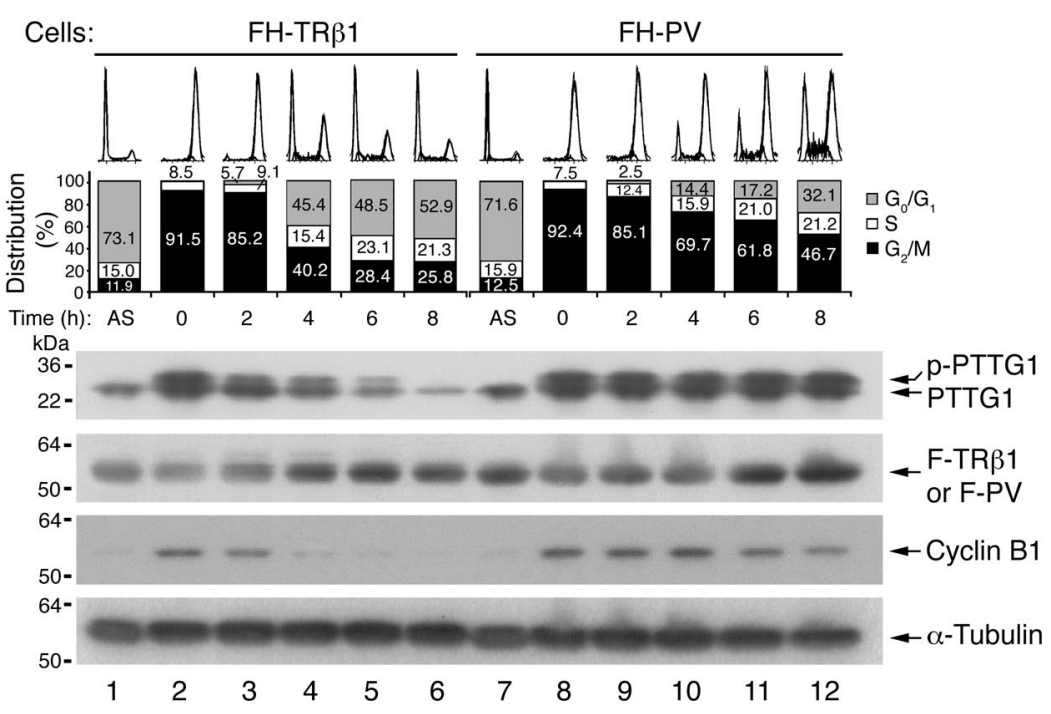

\section{Figure 10}

Aberrant accumulation of PTTG1 induced by PV impedes mitotic progression. FH-TR $\beta 1$ and FH-PV cells were synchronized in prometaphase/metaphase by thymidine/nocodazole block. Synchronized cells were collected (designated $t=0$ hours) and then released by changing to growth media containing $20 \%$ FBS. Cells harvested at various time points after release were subjected to Western blot and fluorescence-activated cell sorting analyses. An asynchronous population of FH-TR $\beta 1$ and FH-PV cells were also examined. The protein abundance of PTTG1, F-TR $\beta 1$, F-PV, cyclin B1 and the loading control $\alpha$-tubulin was determined by Western blot analysis similar to that in Figure 5. in these thyroid tumor cells occur in vivo and not from exogenous transfection. All 7 cell lines show abnormal karyotypes with chromosome numbers ranging from near diploid (39-42 chromosomes) to hypotetraploid (63-79 chromosomes). These 7 cell lines exhibit a variety of structural chromosomal aberrations including common recurrent translocations and deletions (12). Taken together, these observations provide a strong link of PV-induced overexpressed PTTG1 with aneuploidy in vivo.

However, at present, despite the close association of elevated PTTG1 with aneuploidy in the thyroid tumors of $T R \beta^{P V / P V}$ mice (12) and in human thyroid cancer (22), whether overexpression of PTTG1 causes thyroid cancer remains unclear. cDNA microarray analysis of thyroid tumors of $T R \beta^{P V / P V}$ mice indicates that complex alterations of multiple signaling pathways are associated with thyroid carcinogenesis (7). It is likely that the chromosomal abnormalities caused by aberrantly increased PTTG1 contribute to the progression rather than the development of thyroid cancer. This issue will require further study.

Studies so far have shown that the deleterious effects of TR $\beta$ mutants in causing RTH are mediated via dominant-negative actions at the transcriptional level $(5,30)$. A prominent example is the persistently elevated levels of serum thyroid-stimulating hormone (TSH) due to the loss of the negative regulation of TSH $\beta$ and the $\alpha$-glycoprotein common subunit genes caused by the dominant-negative effects of $\operatorname{TR} \beta$ mutants at the transcription level (3). The present findings unveil what we believe to be a new mode of action of TR $\beta$ mutants that takes place at the posttranslational level, namely, the blocking of the normal degradation of PTTG1 via complex formation, thus leading to genetic instability. The function of PV in the stabilization of cellular proteins may not be limited to PTTG1. Many

Figure 11 key signaling molecules involved in cell cycle regulation, cellular adhesion, cell proliferation, and apoptosis are degraded by the proteasome. It is reasonable to postulate that other key effectors of thyroid carcinogenesis could fail to be properly degraded by proteasome due to the action of TR $\beta$ mutants. Therefore, the stabilization of critical regulators that could act as tumor promoters by TR $\beta$ mutants may be one key mechanism by which TR $\beta$ mutants function as oncogenes. The identification in future studies of such key molecules that are dysregulated will further our understanding of the molecular basis of thyroid carcinogenesis.

Further work is needed to elucidate detailed molecular mechanisms by which the direct interaction of the liganded TR $\beta 1$ with SRC-3/PA28 $\gamma$ activates the degradation of TR $\beta 1$ and PTTG1. However, it is reasonable to expect that this mode of activated degradation mediated by SRC-3/PA28 $\gamma$ is not limited to the liganded TR $\beta 1$ and PTTG1. SRC-3 is widely expressed in many tissues and has been shown to associate with many nuclear proteins to regulate their functions (26). Therefore, this mode of posttranslational regulation of cellular proteins mediated by SRC-3/PA28 $\gamma$ - that,

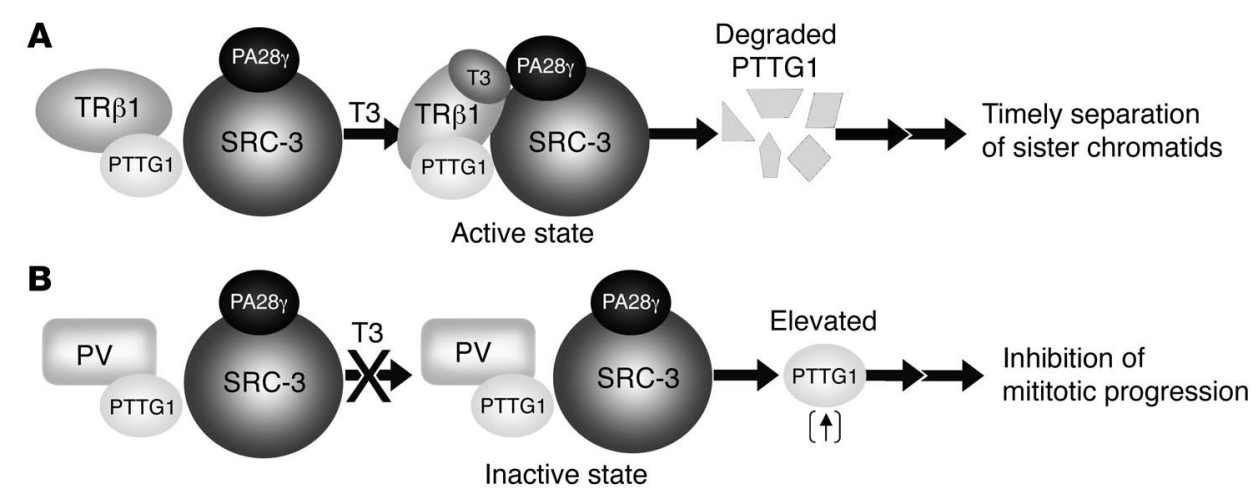

Proposed molecular model for the liganded TR $\beta 1$-dependent, SRC-3/PA28 $\gamma$-activated degradation of PTTG1. (A) The direct interaction of TR $\beta 1$ with SRC-3 induced by the binding of T3 results in the formation of liganded TR $\beta 1 /$ PTTG1/SRC-3/PA28 $\gamma$ complexes that activate the degradation of PTTG1. This degradation leads to timely separation of sister chromatids. (B) PV also forms complexes with PTTG1, but since PV does not bind T3, it cannot directly bind to SRC-3/PA28 $\gamma$ to activate degradation. This leads to elevated PTTG1 and results in inhibition of mitotic progression. 
to our knowledge, is novel - could be an important regulatory mechanism for cellular functions.

\section{Methods}

$P V$ mice. The animal protocol used in the present study has been approved by the National Cancer Institute Animal Care and Use Committee. The mice harboring the TR $\beta P V$ gene were prepared, genotyped, and bred as previously described (3). The wild-type littermates were used as controls.

Plasmids and antibodies. The construction of plasmids F-TR $\beta 1$ [pFlag(f)TR $\beta 1$ ] and F-PV [pFlag(f)-PV] was performed using TR $\beta 1$ (pCLC51) (31) or PV expression vectors (pCLC51PV) (32) as templates for PCR cloning with a Pfx DNA Polymerase kit (Invitrogen). The sequences of these plasmids were confirmed by DNA sequencing.

The mouse PTTG1 expression plasmid, kindly provided by S. Melmed (UCLA, Los Angeles, California, USA), was used as a PCR cloning template for construction of other PTTG1-related plasmids. We used pFlag-CMV2 (Sigma-Aldrich) to generate F-PTTG1; pcDNA3.1(+) (Invitrogen) to generate pcDNA3.1-PTTG1; and pGEX-6p-1 (Amersham Biosciences) to generate GST-PTTG1, GST-PTTG1 $\Delta$ C, and GST-PTTG1 $1 \mathrm{~N}$ fusion constructs. IMAGE Consortium Clone-Human 5815153 (ATCC) was used as a template to clone full-length PA28 $\gamma$ into pcDNA3. $1^{+}$and pFlag-CMV2 vectors. Primers containing EcoRI/BamHI cloning sites and a Pfx DNA Polymerase kit were used in PCR reactions. The PCR products were digested by EcoRI and BamHI and inserted into corresponding vectors. All the plasmids constructed in this study were confirmed by DNA sequencing.

The expression vector for F-TR $\beta 1(170-461)$, Flag-CMV-TR $\beta$ Nsi, was constructed by cloning the full-length TR $\beta 1$ into Flag-CMV mammalian expression vector (Sigma-Aldrich), followed by using an Nsi I restriction site within the TR $\beta 1$ sequence to delete the nucleotides encoding the first 169 TR $\beta 1$ residues. The sequence was confirmed by DNA sequencing.

The $\mathrm{T} 7$ expression plasmids used for in vitro transcription/translation were pCJ3 (TRß1), pJL08 (ED41), pJL06 (MD32), pCJ4 (KD25), pCJ7 (KP24), and PGEM-PV (PV), which have been previously described $(6,33,34)$.

GST pull-down assays. A GST/glutathione binding system was used to assess the physical interaction of PTTG1 with TR $\beta 1$ or PV, as described by Furumoto et al. (35). The plasmids used for in vitro transcription/ translation were pcDNA3.1-PTTG1 (mouse), pCJ3 (TRß1), pJL08 (ED41), pJL06 (MD32), pCJ4 (KD25), pCJ7 (KP24), and pGEM-PV (PV). After in vitro transcription/translation, the translated $\left[{ }^{35} \mathrm{~S}\right]$-labeled proteins were quantified by the intensities of bands after SDS gel electrophoresis and autoradiography. Equal amounts of $\left[{ }^{35} \mathrm{~S}\right]$-labeled proteins (PTTG1, TR $\beta 1$, $\mathrm{PV}$, or truncated TR $\beta 1$ proteins) were used in the binding to GST-TR $\beta 1$, GST-PTTG1, or GST-PTTG1 $1 \Delta$ C or GST-PTTG1 $\Delta \mathrm{N}(2 \mu \mathrm{g})$.

Establishment of FH-TR $\beta 1$ and FH-PV cells. Human TR $\beta 1$ and PV cDNAs were cloned into pFH-IRESneo plasmid (ref. 36; a generous gift of R.G. Roeder, Rockefeller University, New York, New York, USA) to obtain F-TR $\beta 1$ and F-PV, respectively. HeLa cells were transfected with F-TR $\beta 1$ or F-PV and selected with $500 \mu \mathrm{g} / \mathrm{ml} \mathrm{G418} \mathrm{(Invitrogen)} \mathrm{for} 3$ weeks as described previously (37). G418-resistant colonies expressing Flag-HA-tagged proteins were expanded for subsequent experiments. The expression of TR $\beta 1$ or PV protein was verified by Western blot analysis using anti-Flag (Sigma-Aldrich), antiTR $\beta 1$ C4 (38), or anti-PV 302 antibodies (32). Cell lines stably expressing TR $\beta 1$ or PV were designated as FH-TR $\beta 1$ or FH-PV cells, respectively.

Determination of cellular PTTG1 levels. The F-PTTG1 levels were assessed in CV-1 cells as well as FH-TR $\beta 1$ and FH-PV cells by Western blot analyses. F-PTTG1 expression plasmid ( $3 \mu \mathrm{g})$ was cotransfected with or without the expression plasmid for F-TR $\beta 1$ ( $3 \mu \mathrm{g})$ or F-PV $(3 \mu \mathrm{g})$. After 24 hours, cells were incubated in the presence or absence of $100 \mathrm{nM} \mathrm{T3}$. In some dishes, the proteasome inhibitor MG132 $(50 \mu \mathrm{M})$ was added to the medium. After 16 hours, cells were harvested and lysed, and the cellular PTTG1 levels were determined by Western blot analysis as described previously (35) except that, in addition to protease inhibitors, $5 \mathrm{mM} \mathrm{N}$-ethylmaleimide (SigmaAldrich), $10 \mathrm{nM}$ ubiquitin aldehyde (Sigma-Aldrich), $0.2 \mu \mathrm{M}$ okadaic acid, $10 \mathrm{mM} \mathrm{NaF}$, and $1 \mathrm{mM} \mathrm{Na}_{3} \mathrm{VO}_{4}$ were added in the lysis buffer. Anti-Flag antibody $(0.5 \mu \mathrm{g} / \mathrm{ml}$; catalog no. F3165; Sigma-Aldrich) was used to determine F-PTTG1, F-TR $\beta 1$, and F-PV protein levels.

PTTG1 abundance was also assessed in vivo using mouse thyroids from wild-type, SRC-3 $3^{--}, T R \beta^{P V / P V S R C-3^{+/+}}$, and TR $\beta^{P V / P V S R C-3^{-/-}}$mice. Thyroid glands were dissected, washed with PBS, and homogenized on ice in cell lysis buffer containing $50 \mathrm{mM}$ Tris, $100 \mathrm{mM} \mathrm{HCl}, 0.5 \%$ Triton X-100, $0.2 \mu \mathrm{M}$ okadaic acid, $100 \mathrm{mM} \mathrm{NaF}, 0.2 \mathrm{mM} \mathrm{Na}_{3} \mathrm{VO}_{4}$, and proteinase inhibitor tablet (Complete, Mini, EDTA-free; Roche Diagnostics). The lysate was centrifuged for 15 minutes at $12,000 \mathrm{~g}$ at $4^{\circ} \mathrm{C}$, and the protein concentration in the supernatant was determined using Coomassie Plus Protein Assay Reagent (Pierce) with bovine serum albumin as standard. Lysates (50 $\mu \mathrm{g})$ were used for the determination of PTTG1 by Western blot analysis as described above. Primary antibodies used in the Western blot analysis were polyclonal anti-human PTTG1 antibodies $(1 \mu \mathrm{g} / \mathrm{ml}$; catalog no. 34-1500; Invitrogen) together with polyclonal anti-mouse PTTG1 antibodies we developed using recombinant mouse PTTG1 produced and purified from bacteria as antigen (designated as $\mathrm{Ab} 77 ; 1 \mu \mathrm{g} / \mathrm{ml}$ ). For the control of protein loading, anti- $\alpha$-tubulin was used (catalog no. T6199; Sigma-Aldrich).

RNA interference assays. Control siRNA (siCONTROL Non-targeting siRNA \#2, D-001210-02-05) and siRNA against PA28 $\gamma$ (siGENOME SMARTpool reagent M-012133-00) were purchased from Dharmacon. For RNA interference experiments, CV-1 cells were cultured in DMEM with $3 \%$ $\mathrm{vol} / \mathrm{vol} \mathrm{FBS}$ and prepared at $60 \%$ confluence 6 hours before transfection. Each siRNA (40 nM) was transfected into CV-1 cells with Lipofectamine 2000 (Invitrogen) following the manufacturer's instructions. After 24 hours, the cells were cotransfected with $10 \mu \mathrm{g}$ of the expression plasmid for F-TR $\beta 1$ or the control plasmid and $40 \mathrm{nM}$ siRNA using Lipofectamine 2000 and then incubated for 24 hours. Cells were then cultured in media with or without $100 \mathrm{nM} \mathrm{T} 3$ and incubated for an additional 24 hours. The protein concentration and subsequent Western blot analysis were performed as described above.

Analysis of GAL4-PTTG1 transcription activity. For the GAL4-PTTG1 reporter assay, plating and transfection were performed in a manner similar to that described previously (35). Briefly, GAL4 or GAL4-PTTG1 (0.2 $\mu \mathrm{g}$; kindly provided by L. Pei, UCLA, Los Angeles, California, USA) and the expression vector of TR $\beta 1$ or $\mathrm{PV}(0.2 \mu \mathrm{g})$ or the empty vector (pCDM8) were cotransfected with the reporter plasmid of GAL4 (pE1b-4XUAS-luc; $1 \mu \mathrm{g}$ ) into CV-1 cells. The luciferase activity induced by GAL4-PTTG1 was normalized by the corresponding activity induced by GAL4 alone, and the data are shown as fold activation of GAL4-PTTG1 over GAL4.

Analysis of the association of SRC-3 with TR $\beta 1$ or PV and with PA28 $\gamma$ in cells. The association of SRC-3 with PA28 $\gamma$ and TR $\beta 1$ or PV in cells was determined by coimmunoprecipitation. To determine the interaction of endogenous SRC-3 with endogenous or transfected PA28 $\gamma$, FH-TR $\beta 1$ cells were cultured without transfection or transfected with F-PA28 $\gamma(5 \mu \mathrm{g})$ in the presence or absence of $100 \mathrm{nM} \mathrm{T3}$ as described previously (35). Forty-eight hours later, cells were harvested as described previously (23), and cell lysates were immunoprecipitated with SRC-3 antibody (a generous gift from R.-C. Wu, Baylor College of Medicine, Houston, Texas, USA), followed by Western blot analysis using anti-PA28 $\gamma$ antibody (1:150 dilution, catalog no. 38-3800; Invitrogen) or anti-Flag antibody. Similarly, to investigate the interaction of TR $\beta 1$ or PV with SRC-3, CV-1 or HEK293 cells were cotransfected with pcDNA3.1-AIB1 and F-TR $\beta 1$ or F-PV ( $5 \mu \mathrm{g}$ each) in the presence or absence of $100 \mathrm{nM}$ T3. Flag-M2 beads (catalog no. A2220; SigmaAldrich) were used for immunoprecipitation, and anti-SRC-3 antibody was used for Western blot analysis. 
Histological and immunohistochemical analysis. Immunohistochemical localization of PTTG1 was performed in a manner similar to that previously described (8). The anti-PTTG1 antibody was purchased from Invitrogen. Quantification of the intensity of the HRP signal was performed by applying an automated function (Autolevels adjustment) in Adobe Photoshop version 7.0, and the density of selected spots in the cytoplasm of cells was measured ( 5 per image) by the Histograms function in Photoshop after selection using the Magic Wand tool, from which the percentage density values \pm SD were calculated. A similar operation was performed on the controls, and these values were subtracted from those for the signals derived from anti-PTTG1 antibodies.

Fluorescence confocal microscopy. Subcellular localization of TR $\beta 1, \mathrm{PV}$, and PTTG1 was visualized by fluorescence confocal microscopy. CV-1 cells $\left(1-1.3 \times 10^{5}\right.$ cells) were transfected with $1.5 \mu \mathrm{g}$ F-TR $\beta 1$ or F-PV. After 24 hours, cells were treated with or without $100 \mathrm{nM}$ T3. After culturing cells for an additional 24 hours, cells were washed twice in PBS, fixed with freshly prepared $4 \%$ paraformaldehyde (5 minutes at room temperature), and permeabilized with $0.5 \%$ Triton X-100 in PBS (10 minutes at room temperature). Nonspecific binding of the antibodies was blocked with bovine serum albumin (3\%) for 10 minutes before incubation with the anti-Flag antibody $(0.5 \mu \mathrm{g} / \mathrm{ml}$, catalog no. F3165; Sigma-Aldrich) and anti-PTTG1 antibody $(10 \mu \mathrm{g} / \mathrm{ml}$, catalog no. $34-1500$; Invitrogen $)$ at $4^{\circ} \mathrm{C}$ overnight. The cells were subsequently incubated with $1 \mu \mathrm{g} / \mathrm{ml}$ of Alexa Fluor 488 fragment of goat anti-mouse IgG (catalog no. A11017; Invitrogen) or antirabbit Texas Red ( $1 \mu \mathrm{g} / \mathrm{ml}$; Invitrogen). Nuclei were also stained with DAPI (Vector Laboratories). Laser confocal scanning images were captured with the use of an Ultraview (PerkinElmer) confocal head on a Zeiss TV200 inverted microscope. The localization of PTTG1, TR $\beta 1$, and PV in cells arrested at the $G_{2} / M$ phase by thymidine/nocodazole treatment followed by 6-hour release were visualized similarly.

Cell cycle analysis. FH-TR $\beta 1$ and FH-PV cells were grown in DMEM with $10 \% \mathrm{vol} /$ vol FBS supplemented with $250 \mu \mathrm{M}$ G418. FH-TR $\beta 1$ and $\mathrm{FH}-\mathrm{PV}$ cells were arrested in the $\mathrm{G}_{2} / \mathrm{M}$ phase by thymidine/nocodazole block in a manner similar to that described by Choudhury et al. (39). Briefly, FH-TR $\beta 1$ and FH-PV cells $\left(3.0 \times 10^{6}\right.$ cells $)$ were treated with 2.5 $\mathrm{mM}$ thymidine (Sigma-Aldrich) for 14 hours in DMEM containing $10 \%$ FBS and then released from the thymidine block for 5 hours. The $\mathrm{G}_{2} / \mathrm{M}$ phase-arrested cells were further treated with $0.5 \mu \mathrm{M}$ nocodazole (SigmaAldrich) in DMEM containing 10\% FBS for 16 hours. To release the cells from the thymidine/nocodazole block, cells were cultured in DMEM containing $20 \%$ FBS.

Cells were also synchronized in the $\mathrm{G}_{0} / \mathrm{G}_{1}$ phase by culturing in DMEM supplemented with $0.5 \%$ vol/vol FBS for 72 hours (39). Cells were arrested in the $\mathrm{S}$ phase by a double thymidine block (i.e., two 16-hour incubation periods in $2.5 \mathrm{mM}$ thymidine with 8 hours' release after the first block). Cells in the $\mathrm{S}$ phase were harvested 4 hours after release from the second block by culturing in growth medium containing 10\% FBS (40). Cells arrested in different cell cycles were confirmed by flow cytometry (BD). For fluorescence-activated cell sorting analysis, the cells were stained with propidium iodide and analyzed on BD Biosciences FACSCalibur using CellQuest software version 3.0. The percentage of cells in $G_{1}, S$, or $G_{2} / M$ were calculated using FlowJo Cell Cycle platform (Tree Star Inc.).

Statistics. All data are expressed as mean \pm SEM or mean \pm SD. Statistical analysis was performed using 1-way ANOVA or unpaired 2-tailed Student's $t$ test. $P$ values less than 0.05 were considered to be significant.

\section{Acknowledgments}

We wish to thank Paul Meltzer for the pcDNA3.1-AIB1, Shlomo Melmed for pCRII-mPTTG1, Lin Pei for the pGAL4-PTTG1 plasmids, Robert G. Roeder for the pFH-IRESneo plasmid, and Ray-Chang Wu for anti-SRC-3 antibodies. This research was supported in part by the Intramural Research Program of the National Cancer Institute, NIH.

Received for publication March 21, 2006, and accepted in revised form August 15, 2006.

Address correspondence to: Sheue-yann Cheng, Laboratory of Molecular Biology, National Cancer Institute, 37 Convent Drive, Room 5128, Bethesda, Maryland 20892-4264, USA. Phone: (301) 496-4280; Fax: (301) 402-1344; E-mail: chengs@mail.nih.gov.

Hao Ying, Fumihiko Furuya, and Li Zhao contributed equally to this work.
1. Kroll, T.G. 2004. Molecular events in follicular thyroid tumors. Cancer Treat. Res. 122:85-105.

2. Suzuki, H., Willingham, M.C., and Cheng, S.Y. 2002. Mice with a mutation in the thyroid hormone receptor beta gene spontaneously develop thyroid carcinoma: a mouse model of thyroid carcinogenesis. Thyroid. 12:963-969.

3. Kaneshige, M., et al. 2000. Mice with a targeted mutation in the thyroid hormone beta receptor gene exhibit impaired growth and resistance to thyroid hormone. Proc. Natl. Acad. Sci. U. S. A. 97:13209-13214.

4. Parrilla, R., Mixson, A.J., McPherson, J.A., McClaskey, J.H., and Weintraub, B.D. 1991. Characterization of seven novel mutations of the c-erbA $\beta$ gene in unrelated kindreds with generalized thyroid hormone resistance. Evidence for two "hot spot" regions of the ligand binding domain. J. Clin. Invest. 88:2123-2130.

5. Yen, P.M. 2003. Molecular basis of resistance to thyroid hormone. Trends Endocrinol. Metab. 14:327-333.

6. Meier, C.A., et al. 1992. Variable transcriptional activity and ligand binding of mutant beta $13,5,3^{\prime}$ triiodothyronine receptors from four families with generalized resistance to thyroid hormone. Mol. Endocrinol. 6:248-258.

7. Ying, H., et al. 2003. Alterations in genomic profiles during tumor progression in a mouse model of follicular thyroid carcinoma. Carcinogenesis.
24:1467-1479.

8. Ying, H., et al. 2003. Mutant thyroid hormone receptor beta represses the expression and transcriptional activity of peroxisome proliferator-activated receptor gamma during thyroid carcinogenesis. Cancer Res. 63:5274-5280.

9. Roque, L., Rodrigues, R., Pinto, A., Moura-Nunes, V., and Soares, J. 2003. Chromosome imbalances in thyroid follicular neoplasms: a comparison between follicular adenomas and carcinomas. Genes Chromosomes Cancer. 36:292-302.

10. Tung, W.S., et al. 1997. Allelotype of follicular thyroid carcinomas reveals genetic instability consistent with frequent nondisjunctional chromosomal loss. Genes Chromosomes Cancer. 19:43-51.

11. Rodrigues-Serpa, A., Catarino, A., and Soares, J. 2003. Loss of heterozygosity in follicular and papillary thyroid carcinomas. Cancer Genet. Cytogenet. 141:26-31.

12. Zimonjic, D.B., Kato, Y., Ying, H., Popescu, N.C., and Cheng, S.Y. 2005. Chromosomal aberrations in cell lines derived from thyroid tumors spontaneously developed in TRbetaPV/PV mice. Cancer Genet. Cytogenet. 161:104-109.

13. Yu, R., and Melmed, S. 2001. Oncogene activation in pituitary tumors. Brain Pathol. 11:328-341.

14. Pei, L., and Melmed, S. 1999. Isolation and characterization of a pituitary tumor-transforming gene (PTTG). Mol. Endocrinol. 11:433-441.
15. Heaney, A.P., Nelson, V., Fernando, M., and Horwitz, G. 2001. Transforming events in thyroid tumorigenesis and their association with follicular lesions. J. Clin. Endocrinol. Metab. 86:5025-5032.

16. Kim, D.S., McCabe, C.J., Buchanan, M.A., and Watkinson, J.C. 2003. Oncogenes in thyroid cancer. Clin. Otolaryngol. Allied Sci. 28:386-395.

17. Heaney, A.P., et al. 2000. Expression of pituitarytumour transforming gene in colorectal tumours. Lancet. 355:716-719.

18. Zhang, X., et al. 1999. Pituitary tumor transforming gene (PTTG) expression in pituitary adenomas. J. Clin. Endocrinol. Metab. 84:761-767.

19. Dominguez, A., et al. 1998. hPTTG, a human homologue of rat pttg, is overexpressed in hematopoietic neoplasms. Evidence for a transcriptional activation function of hPTTG. Oncogene. 17:2187-2193.

20. Yu, R., Heaney, A.P., Lu, W., Chen, J., and Melmed, S. 2000. Pituitary tumor transforming gene causes aneuploidy and p53-dependent and p53-independent apoptosis. J. Biol. Chem. 275:36502-36505.

21. Yu, R., Lu, W., Chen, J., McCabe, C.J., and Melmed, S. 2003. Overexpressed pituitary tumor-transforming gene causes aneuploidy in live human cells. Endocrinology. 144:4991-4998.

22. Kim, D., et al. 2005. Pituitary tumour transforming gene (PTTG) induces genetic instability in thyroid cells. Oncogene. 24:4861-4866.

23. Li, X., et al. 2006. The SRC-3/AIB1 coactivator is 
degraded in a ubiquitin- and ATP-independent manner by the REGgamma proteasome. Cell. 124:381-392

24. Dace, A., et al. 2000. Hormone binding induces rapid proteasome-mediated degradation of thyroid hormone receptors. Proc. Natl. Acad. Sci.U. S. A. 97:8985-8989.

25. Gao, X., Li, J., Pratt, G., Wilk, S., and Rechsteiner, M. 2004. Purification procedures determine the proteasome activation properties of REG gamma (PA28 gamma). Arch. Biochem. Biophys. 425:158-164.

26. Leonard, D.M., and O'Malley, B.W. 2005. Expanding functional diversity of the coactivators. Trends Biochem. Sci. 30:126-132.

27. Zhou, H., McGarry, T.J., Bernal, T., and Kirschner, M.W. 1999. Identification of a vertebrate sister-chromatid separation inhibitor involved in transformation and tumorigenesis. Science. 285:418-422.

28. Ramos-Morales, F., et al. 2000. Cell cycle regulated expression and phosphorylation of hpttg protooncogene product. Oncogene. 19:403-409.

29. Yu, R., Ren, S.G., Horwitz, G.A., Wang, Z., and Melmed, S. 2000. Pituitary tumor transforming gene (PTTG) regulates placental JEG-3 cell division and survival: evidence from live cell imaging. Mol. Endocrinol. 14:1137-1146.

30. Cheng, S.Y. 2005. Thyroid hormone receptor mutations and disease: beyond thyroid hormone resistance. Trends Endocrinol. Metab. 16:176-182.

31. Lin, K.H., Ashizawa, K., and Cheng, S.Y. 1992. Phosphorylation stimulates the transcriptional activity of the human $\beta 1$ thyroid hormone nuclear receptor. Proc. Natl. Acad. Sci. U. S.A. 89:7737-7741.

32. Zhang, X.Y., et al. 2002. Differential expression of thyroid hormone receptor isoforms dictates the dominant negative activity of mutant $\beta$ receptor. Mol. Endocrinol. 16:2077-2092.

33. Lin, K.H., Parkison, C., McPhie, P., and Cheng, S.Y. 1991. An essential role of domain D in the hormone-binding activity of human beta 1 thyroid hormone nuclear receptor. Mol. Endocrinol. 5:485-492.

34. Meier, C.A., et al. 1993. Interaction of human $\beta 1$ thyroid hormone receptor and its mutants with DNA and retinoid $X$ receptor $\beta$. T3 response element-dependent dominant negative potency. J. Clin. Invest. 92:1986-1993.

35. Furumoto, H., et al. 2005. An unliganded thyroid hormone beta receptor activates the cyclin
D1/cyclin-dependent kinase/retinoblastoma/E2F pathway and induces pituitary tumorigenesis. Mol. Cell. Biol. 25:124-135.

36. Martinez, E., et al. 2001. Human STAGA complex is a chromatin-acetylating transcription coactivator that interacts with pre-mRNA splicing and DNA damage-binding factors in vivo. Mol. Cell. Biol. 21:6782-6895.

37. Malik, S., and Roeder, R.G. 2003. Isolation and functional characterization of the TRAP/mediator complex. Methods Enzymol. 364:257-284.

38. Bhat, M.K., McPhie, P., Ting, Y.T., Zhu, X.-Y., and Cheng, S.-Y. 1995. Structure of the carboxy-terminal region of thyroid hormone nuclear receptors and its possible role in hormone-dependent intermolecular interactions. Biochemistry. 34:10591-10599.

39. Choudhury, A.D., Xu, H., and Baer, R. 2004. Ubiquitination and proteasomal degradation of the BRCA1 tumor suppressor is regulated during cell cycle progression. J. Biol. Chem. 279:33909-33918.

40. Jin, D.Y., Spencer, F., and Jeang, K.T. 1998. Human $\mathrm{T}$ cell leukemia virus type 1 oncoprotein Tax targets the human mitotic checkpoint protein MAD1. Cell. 93:81-91. 